\title{
Atmospheric radiative effects of an in situ measured Saharan dust plume and the role of large particles
}

\author{
S. Otto ${ }^{1}$, M. de Reus ${ }^{2}$, T. Trautmann ${ }^{1}$, A. Thomas ${ }^{2}$, M. Wendisch ${ }^{2}$, and S. Borrmann ${ }^{2}$ \\ ${ }^{1}$ Remote Sensing Technology Institute (IMF), DLR Oberpfaffenhofen, Germany \\ ${ }^{2}$ Institute for Atmospheric Physics, Johannes Gutenberg University Mainz, Germany
}

Received: 19 April 2007 - Published in Atmos. Chem. Phys. Discuss.: 4 June 2007

Revised: 29 August 2007 - Accepted: 14 September 2007 - Published: 21 September 2007

\begin{abstract}
This work will present aerosol size distributions measured in a Saharan dust plume between 0.9 and $12 \mathrm{~km}$ altitude during the ACE-2 campaign 1997. The distributions contain a significant fraction of large particles of diameters from 4 to $30 \mu \mathrm{m}$. Radiative transfer calculations have been performed using these data as input. Shortwave, longwave as well as total atmospheric radiative effects (AREs) of the dust plume are investigated over ocean and desert within the scope of sensitivity studies considering varied input parameters like solar zenith angle, scaled total dust optical depth, tropospheric standard aerosol profiles and particle complex refractive index. The results indicate that the large particle fraction has a predominant impact on the optical properties of the dust. A single scattering albedo of $\omega_{0}=0.75-0.96$ at $550 \mathrm{~nm}$ was simulated in the entire dust column as well as 0.76 within the Saharan dust layer at $\sim 4 \mathrm{~km}$ altitude indicating enhanced absorption. The measured dust leads to cooling over the ocean but warming over the desert due to differences in their spectral surface albedo and surface temperature. The large particles absorb strongly and they contribute at least $20 \%$ to the ARE in the dusty atmosphere.

From the measured size distributions modal parameters of a bimodal lognormal column volume size distribution were deduced, resulting in a coarse median diameter of $\sim 9 \mu \mathrm{m}$ and a column single scattering albedo of 0.78 at $550 \mathrm{~nm}$. A sensitivity study demonstrates that variabilities in the modal parameters can cause completely different AREs and emphasises the warming effect of the large mineral dust particles.
\end{abstract}

\section{Introduction}

As an integral part of the atmospheric aerosol, mineral dust plays an important role in the Earth's climate system. Dust

Correspondence to: S. Otto

(sebastian.otto@dlr.de) particles modify the transport of the shortwave as well as longwave radiation through the atmosphere by scattering and absorption processes. Depending on their size distribution, chemical composition and shape (determining their optical properties extinction coefficient, single scattering albedo and phase function), and furthermore depending on the vertical position/extent of a dust layer as well as the local surface albedo, mineral dust particles may have a positive (heating of the climate system) or negative (cooling) radiative effect (Claquin et al., 1998; Sokolik and Toon, 1999; Sokolik, 1999; Myhre and Stordal, 2001).

Several studies about the atmospheric radiative effect (ARE) of mineral dust within the atmosphere exist. Quijano et al. (2000a) calculated solar, thermal and total radiative heating rates as well as radiances and the ARE of dust in order to analyse its influence on the radiation budget of dusty atmospheres. Quijano et al. (2000b) reported that the vertical distribution of the dust, its optical properties, the presence of clouds, the surface albedo of the bottom of the atmosphere (BOA) or the sun position have a significant impact on the radiative effect of dust. Total heating rates are always positive, yielding radiative heating of dust layers forced by increasing dust loading. Furthermore, Quijano et al. (2000a) showed that the diurnally averaged radiative impact at the top of the atmosphere (TOA) depends on the mineralogical composition of the dust. The cloudless total ARE of Saharan dust at the TOA was estimated to be negative $\left(\sim-35 \mathrm{~W} \mathrm{~m}^{-2}\right)$ over the ocean for a cosine of the solar zenith angle (SZA) of $\mu_{o}=0.25$ and a dust optical depth of $\tau(0.5 \mu \mathrm{m})=1.0$. A positive ARE $\left(\sim+65 \mathrm{~W} \mathrm{~m}^{-2}\right)$ was simulated over the desert for $\mu_{o}=0.8$ and $\tau(0.5)=1.0$. Moreover, the dust absorption increases with increasing total dust optical depth such that this negative radiative effect is reduced and can turn into the positive. Haywood et al. (2001) estimated the total solar Saharan dust impact at TOA to be about $-60 \mathrm{~W} \mathrm{~m}^{-2}$ and the single scattering albedo $\omega_{o}(0.55)$ about 0.87 . Furthermore, they found an additional heating in the atmospheric column due

Published by Copernicus Publications on behalf of the European Geosciences Union. 


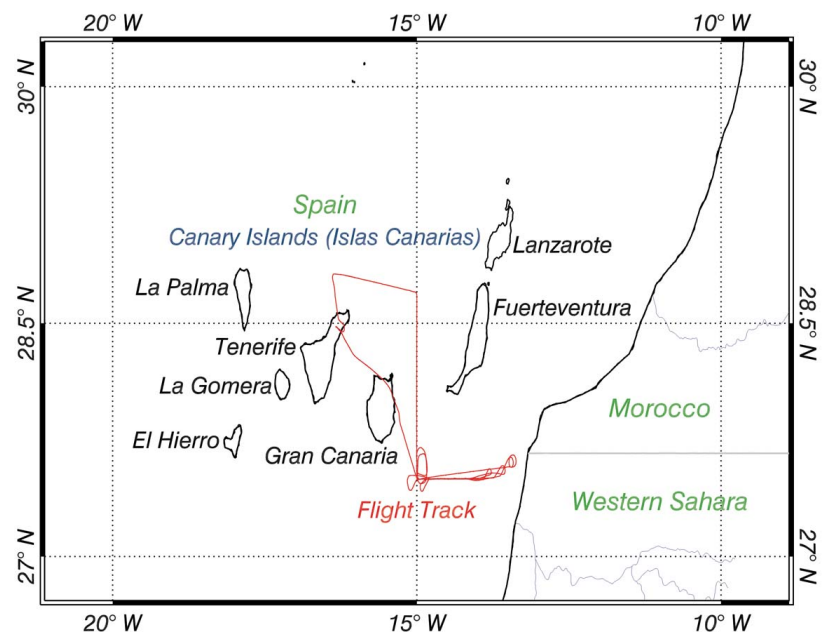

Fig. 1. Flight track (red) of the Cessna Citation on 8 July 1997 during ACE-2 over the Canary Islands.

to dust absorption. Myhre et al. (2003) also predicted a significant negative total ARE of mineral dust from the Sahara. The solar impact values ranged from -115 to $+8 \mathrm{~W} \mathrm{~m}^{-2}$, while the longwave effect was up to $+8 \mathrm{~W} \mathrm{~m}^{-2}$, and the diurnal mean total forcing was found to be close to $-50 \mathrm{~W} \mathrm{~m}^{-2}$. Zhang et al. (2003) reported a monthly-mean longwave ARE of $+7 \mathrm{~W} \mathrm{~m}^{-2}$ over desert under cloudless conditions. Weaver et al. (2002) calculated a summertime ARE ranging from 0 to $-18 \mathrm{~W} \mathrm{~m}^{-2}$ over ocean and from 0 to $+20 \mathrm{~W} \mathrm{~m}^{-2}$ over land. On the other hand, Myhre and Stordal (2001) found a small global mean radiative effect from -0.7 to $0.5 \mathrm{~W} \mathrm{~m}^{-2}$ with different contributions to its sign in certain regions.

This work uses data from the second Aerosol Characterisation Experiment (ACE-2) to estimate the ARE during a dust outbreak over the North Atlantic. ACE-2 was carried out over the North-East Atlantic Ocean between Portugal, the Azores and the Canary Islands during June/July 1997. The main purpose of this experiment was to study the characteristics of natural and anthropogenic aerosols as well as their transformation and removal processes. The ultimate goal was to acquire better estimates of the direct and indirect impact of man-made aerosols on climate. Measurements were performed from several ground-based stations, research aircrafts and a research vessel. A general overview of the campaign and its main results are presented by Raes et al. (2000). The recent paper presents aerosol size distribution measurements in a Saharan dust plume performed onboard the Cessna Citation research aircraft, which was based at Los Rodeos Airport on Tenerife (Canary Islands). The observed aerosol size distributions have been used as input for a radiative transfer model to calculate the ARE of the dust plume.

Section 2 reports on the instrumentation and observations during ACE-2. In Sect. 3 the radiative transfer model package is described as well as the input parameters for the performed sensitivity studies. The optical properties of the mea-
Table 1. Aerosol instrumentation (and its size ranges) onboard the Cessna Citation aircraft during the ACE-2 experiment.

\begin{tabular}{cc}
\hline Instrument & Size range (diameter) \\
\hline Condensation Particle Counter (CPC) & $0.006-1 \mu \mathrm{m}$ \\
Condensation Particle Counter (CPC) & $0.018-1 \mu \mathrm{m}$ \\
Differential Mobility Analyser (DMA) & $0.020-0.15 \mu \mathrm{m}$ \\
Optical Particle Counter (OPC) & $0.11-3.5 \mu \mathrm{m}$ \\
Forward Scattering Spectrometer & \\
Probe (FSSP) & $0.36-31 \mu \mathrm{m}$ \\
\hline
\end{tabular}

sured dust as function of particle size, wavelength and altitude as well as the results of the sensitivity calculations are presented in Sect. 4, which finishes with detailed discussions of the role of large dust particles. Finally, the conclusions of this work are summarised in Sect. 5.

\section{Instrumentation and observations}

On 8 July 1997 a research flight was performed about $50-200 \mathrm{~km}$ off the coast of Africa. A map of the flight track is shown in Fig. 1. During this flight seven isobaric flight legs were flown in the free troposphere between 2.7 and $11.6 \mathrm{~km}$ altitude, in a stacked pattern. Each flight leg lasted for about $15 \mathrm{~min}$, which corresponds to a horizontal distance of about $150 \mathrm{~km}$. On the transfer back to Tenerife a longer isobaric flight leg was conducted in the marine boundary layer at about $0.9 \mathrm{~km}$ altitude.

The aerosol size distributions presented in this work have been composed using the measurements of five instruments onboard the Cessna Citation aircraft during ACE-2, which are summarised in Table 1. A detailed description of the instrumentation can be found in de de Reus et al. (2000a) and de Reus et al. (2000b).

The altitude profiles of the sub-micrometer and coarse mode aerosol number concentration observed during this flight are shown in Fig. 2. The sub-micrometer aerosol number concentration is the concentration measured by the CPC with the $0.006 \mu \mathrm{m}$ cut off diameter $(0.006-1 \mu \mathrm{m})$, and the coarse mode aerosol concentration is the total particle number concentration measured by the FSSP-300 $(0.36-31 \mu \mathrm{m})$. The data has been averaged over $100 \mathrm{~m}$ altitude bins. Both the submicron and coarse mode particle number concentration strongly decreased with altitude within the marine boundary layer up till $1.5 \mathrm{~km}$ altitude. Between 2.7 and $5.8 \mathrm{~km}$ altitude a relatively high coarse mode particle number concentration was observed. Trajectory analyses show that the air masses in this layer originated from arid regions on the North African continent, suggesting that the particles in this layer are Saharan dust aerosols. Within this Saharan dust layer the coarse mode particle number concentration remained roughly constant at about $10 \mathrm{~cm}^{-3}$, while the 


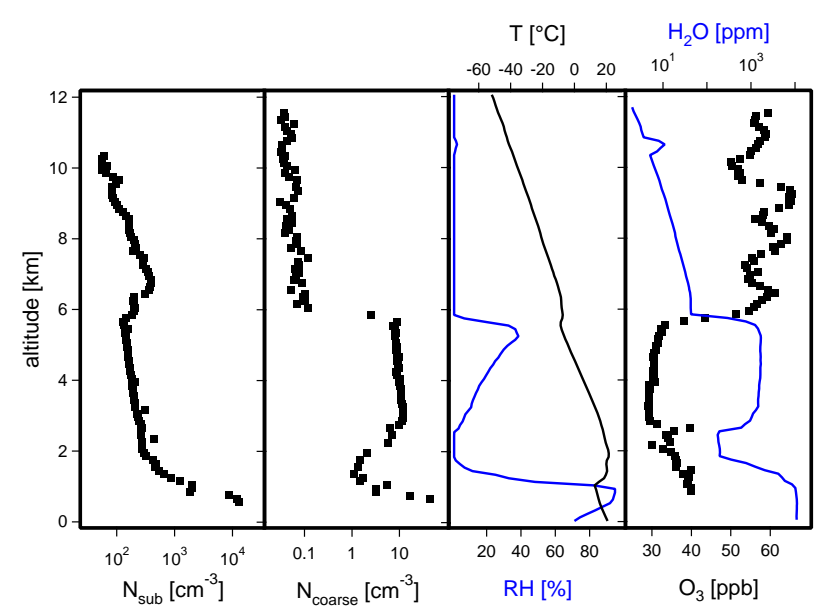

Fig. 2. From left to right: Measured profiles of the sub-micrometer and coarse mode number concentration, the temperature and relative humidity as well as the volume mixing ratio of ozone and water vapour.

submicron particle number concentration showed a gradual decrease from about $250 \mathrm{~cm}^{-3}$ at $2.7 \mathrm{~km}$ altitude to $150 \mathrm{~cm}^{-3}$ at $5.8 \mathrm{~km}$ altitude. In the free troposphere above the dust layer a very low coarse mode particle number concentration was observed (below $0.1 \mathrm{~cm}^{-3}$ ).

Furthermore, Fig. 2 shows the observed water vapour and ozone mixing ratios and the relative humidity $(\mathrm{RH})$ and temperature measured by a radiosonde launched from the island of Tenerife at 06:00 UTC on the same day. Both the marine boundary layer and the dust layer show enhanced values of $\mathrm{RH}$. Within the dust layer, $\mathrm{RH}$ increased from $4 \%$ at $2.5 \mathrm{~km}$ to $35 \%$ at $5.5 \mathrm{~km}$ altitude, which corresponds to a relatively constant water vapour mixing ratio. The temperature profile shows inversions just above and below the dust layer, which inhibit the mixing of the dust air mass with air masses above and below.

Figure 3 depicts the observed aerosol size distributions (by number and volume) on all seven free tropospheric flight legs and on the flight leg in the marine boundary layer. Note that on the top level $(11.6 \mathrm{~km})$ only the coarse mode aerosol size distribution was measured, due to a failure of the instrumentation. For the radiation calculations later in this work, the same sub-micron aerosol size distribution as was observed on the level below $(10.0 \mathrm{~km})$ was assumed. Therefore, the sub-micron part of the size distribution at $11.6 \mathrm{~km}$ altitude is marked grey in Fig. 3. Note also that on the $10.0 \mathrm{~km}$ level, the size distributions derived from the OPC and FSSP do not fit very well together, in contrast to the measurements within the dust layer. Since these particles do not contribute much to the dust optical depth (see Sect. 4), this difference has not been investigated in detail.

From Fig. 3 it becomes obvious that coarse mode particles $\left(D_{p}>1 \mu \mathrm{m}\right)$ were only observed in the marine boundary layer as well as in the Saharan dust layer. Within the ma-

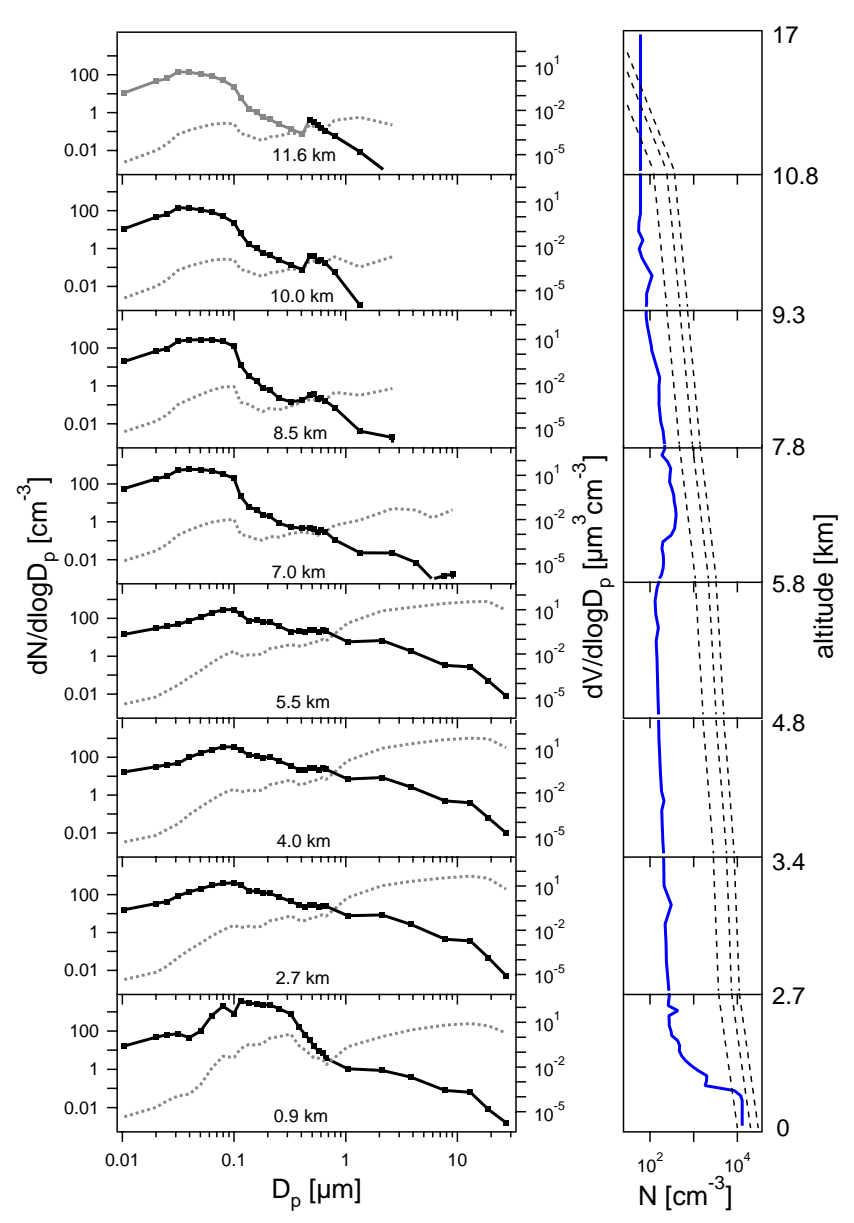

Fig. 3. Observed number (solid) and volume (dotted) aerosol size distributions at eight isobaric flight levels with respective altitudes. The right profile shows the observed total number concentration (solid blue), extrapolated to the tropopause $(>11.6 \mathrm{~km})$ and the ground $(<0.9 \mathrm{~km})$. The dashed profiles in the right panel indicate the number concentrations of the standard maritime and free tropospheric aerosol after Shettle and Fenn (1979).

rine boundary layer, the most dominant mode in the aerosol size distribution was the accumulation mode, whereas in the free troposphere Aitken mode particles dominated the size distribution by number. The total aerosol mass in the marine boundary layer and the Saharan dust layer, however, is clearly determined by coarse mode particles. The dominant volume size distribution mode in these layers is the coarse mode. A more detailed description of the aerosol size distributions observed in the Saharan dust layer is given by de Reus et al. (2000a).

Figure 3 also shows the total particle number concentration, which was observed during the flight. Here, the observed particle number concentrations at 0.9 and $10.4 \mathrm{~km}$ altitude were extrapolated to sea level and the tropopause $(17 \mathrm{~km})$, respectively. For the radiative transfer simulations the observed aerosol size distributions were scaled to the 
Table 2. Widths of the spectral intervals of the model package in different spectral regions.

\begin{tabular}{ccccccc}
\hline$\lambda[\mu \mathrm{m}]$ & 0.225 & 0.888 & 1.056 & 2.351 & 10 & 80 \\
\hline$\Delta \lambda[\mathrm{nm}]$ & 0.05 & 0.79 & 1.12 & 5.52 & 101 & 6410 \\
\hline
\end{tabular}

observed total particle number concentration, as shown in Fig. 3. Note that in the following sections the flight levels are numbered so that the lowest level in the marine boundary layer is level 1 and the top level at $11.6 \mathrm{~km}$ altitude is level 8 .

\section{Radiative transfer model package and sensitivity studies}

In order to calculate atmospheric radiative flux densities, heating rates and, finally, the ARE of mineral dust, the optical properties of the dusty model atmosphere are needed. These are the extinction optical depth, the single scattering albedo and the scattering phase function. In the following the model package and the input parameters for these computations are described as basis for detailed sensitivity studies.

\subsection{Model description}

The model atmosphere with 300 layers and a resolution of $\Delta z=100 \mathrm{~m}$ between bottom and $20 \mathrm{~km}$ altitude as well as of $\Delta z=1 \mathrm{~km}$ between 20 and $120 \mathrm{~km}$ altitude was chosen in accordance with the Air Force Geophysics Laboratory (AFGL) models following Anderson et al. (1986). The profile measurements of meteorological quantities and/or trace gases can be taken into account.

Spectral range and resolution: $200 \mathrm{~nm}$ to $100 \mu \mathrm{m}$ and a wavelength grid according to a constant wave number interval increment of $10 \mathrm{~cm}^{-1}$ leading to a total number of 4990 spectral intervals having widths as given in Table 2. This choice of the wavelength grid has several reasons: On the one hand, a constant spectral wave number increment is useful, since the gas absorption is calculated in the wave number space with the help of the high-resolution transmission molecular absorption database (HITRAN; see http://cfa-www.harvard.edu/HITRAN/), and a higher resolution of wavelength intervals in the LR (longwave, infrared or thermal range, $\lambda>4 \mu \mathrm{m}$ ) would require an enormous computational effort due to the large number of absorption lines. On the other hand, the energy content in the LR and FLR (far LR, $\lambda>20 \mu \mathrm{m}$ ) is much lower than in the SR (shortwave range, $\lambda<4 \mu \mathrm{m}$ ). Additionally, considering the continuum absorption of water vapour (for $\lambda>500 \mathrm{~nm}$ ), each absorption line is only allowed to contribute to the absorption for wave number distances $v-v_{o} \leq 25 \mathrm{~cm}^{-1}$ from the line centre $v_{o}$. The far-wing effect of the lines is described by the continuum. Hence, a wave number increment of $10 \mathrm{~cm}^{-1}$ in conjunction with an interval cut-off of $\pm 15 \mathrm{~cm}^{-1}$ effectively means that the lines outside a particular interval only add to the absorption inside, if their distance to the interval is $\leq 15 \mathrm{~cm}^{-1}$. Thus, their wings influence the absorption in this interval only up to the distance $v-v_{o}=25 \mathrm{~cm}^{-1}$.

Literature data for the spectral complex refractive index of dust are only available for wavelengths up to $39 \mu \mathrm{m}$. Therefore, all the fine-band radiative transfer calculations have been performed up to $39 \mu \mathrm{m}$ (4974 intervals), too.

Two radiation sources are considered on the entire wavelength range of the model: the shortwave solar radiation as well as the longwave Planckian radiation from surface and atmosphere. Both sources overlap in the spectral region close to the wavelength of $4 \mu \mathrm{m}$, which was defined as the bound between SR and LR in the paragraph before. Note further that the considered energy transport in the radiative transfer calculations only covers the spectral range up to the wavelength of $39 \mu \mathrm{m}$. The relative portion of the solar radiation belonging to the spectral range $39-100 \mu \mathrm{m}$ is negligibly small with $\sim 10^{-3} \%$ compared to the entire spectrum. In contrast, the Planckian radiation curves in a temperature range of $290-330 \mathrm{~K}$ contribute $\sim 5 \%$ in this spectral range being equivalent to $\sim 7 \mathrm{Wm}^{-2}$. The corresponding ARE (in $\mathrm{Wm}^{-2}$ ) evaluated for this particular spectral range is much smaller so that any radiative effect in the wavelength range 39-100 $\mu \mathrm{m}$ can be neglected. Moreover, all longwave radiation leaving the Earth to space is transported through the atmospheric window (about $8-13 \mu \mathrm{m}$ ).

The spectral resolution of $1 \mathrm{~cm}^{-1}$ of the MODTRAN ETR extraterrestrial solar spectrum (http: //rredc.nrel.gov/solar/spectra/am0/modtran.html) is taken as upper atmospheric boundary condition averaged to the spectral grid of the model.

The Rayleigh scattering of air molecules is considered after Nicolet (1984), and the gas absorption is computed using the HITRAN of 2004: The spectral absorption cross sections of all HITRAN gases with available mixing ratio profiles are calculated at the 301 atmospheric levels according to their temperature and pressure under the assumption of the Voigt line shape and for the wavelength intervals corresponding to the constant wave number resolution of $10 \mathrm{~cm}^{-1}$. An interval cut-off of $\pm 15 \mathrm{~cm}^{-1}$ is taken into account, so that every absorption line covers a maximum spectral range of $\pm 25 \mathrm{~cm}^{-1}$ from line centre. This corresponds to the definition of the water vapour continuum and to the fact that for larger cut-offs the far wings of far lines outside the interval strongly overestimate the absorption inside. This is because the Voigt line shape is only an approximation for the real line shape, which returns for the far wings the incorrect Lorentzian profile in the lower atmosphere. 
Table 3. Spectral bands for averaging the dust optical properties.

\begin{tabular}{ccc}
\hline Spectral region & Bands & $\begin{array}{c}\text { Band interval } \\
\text { bounds }[\mu \mathrm{m}]\end{array}$ \\
\hline Shortwave (SR) & $1-6$ & $0,0.2,0.7,1.3,1.9,2.5,3.5$ \\
Longwave (LR) & $7-19$ & $3.5,4.545,5.263,5.882$, \\
& & $7.143,8.0,9.091,10.204$, \\
& & $12.5,14.925,18.519,25.0$, \\
& & $35.714,100$ \\
\hline
\end{tabular}

Since HITRAN does not contain line parameters of relevant absorbers in the ultra-violet apart from $\mathrm{O}_{2}$ and $\mathrm{OH}$, several parameterizations or measurements are used to characterise the absorption cross section of $\mathrm{O}_{3}$ (Burrows et al., 1999; Molina and Molina, 1986), $\mathrm{NO}_{2}$ (Burrows et al., 1998), $\mathrm{SO}_{2}$ (Rufus et al., 2003) (http://www-iup.physik. uni-bremen.de/gruppen/molspec/index.html from Bogumil) and $\mathrm{N}_{2} \mathrm{O}$ (Vandaele et al., 1998).

Thus, spectral absorption coefficients as well as spectral level transmittances have been computed, which were averaged over each individual wave number interval in order to compute the corresponding mean layer optical depths.

Aerosol size distributions, given size-bin-resolved or by modal parameters, can be considered to obtain the aerosol's optical properties via Mie computations. This simplification of spherical aerosol particles, see e.g. Lafon et al. (2006), is justified focussing on radiative flux density computations. However, particle non-sphericities will be considered in a following work. Further, standard aerosol optical properties can be chosen (Shettle and Fenn, 1979).

The discrete-ordinate-method after Stamnes et al. (1988) was used with four streams for the comprehensive calculations. Liou et al. (1988) demonstrated the attractiveness of the delta-four-stream approach in terms of accuracy and speed. The following radiative quantities as function of altitude $z$ and wavelength $\lambda$ were computed: the upward $(+)$ and downward (-) radiative flux density (irradiance) $F_{ \pm}(z, \lambda)$ as basis for the shortwave and longwave radiative heating rates

$h_{s, l}(z)=-\frac{1}{c_{p} \rho(z)} \int_{S R / L R} \frac{d F_{n}(z, \lambda)}{d z} d \lambda$

as well as the total heating rate $h_{t}(z):=h_{s}(z)+h_{l}(z)$ where $F_{n}(z, \lambda)=F_{+}(z, \lambda)-F_{-}(z, \lambda)$ is the net flux density as well as $c_{p}$ the specific heat and $\rho$ the air density. Moreover, spectrally integrated quantities were calculated, e.g. the ARE according the Eqs. (2) and (3) in Sect. 3.3.

\subsection{Input parameters for the radiative transfer model}

Meteorological quantities: The measurement profiles of temperature and pressure onboard the aircraft were similar to

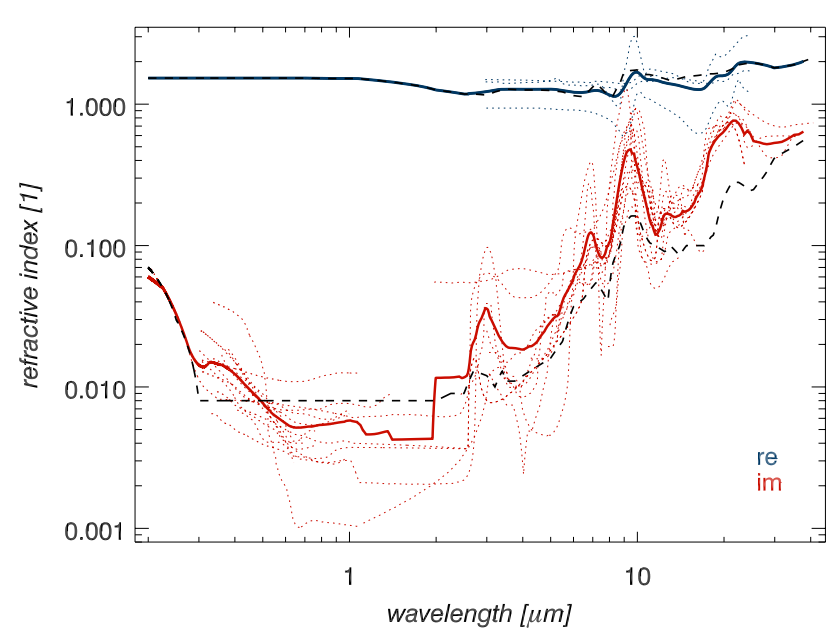

Fig. 4. Real (re) and imaginary (im) parts of the spectral complex refractive indices of mineral dust. The dotted lines show various curves from literature data, and the solid curves were calculated from the dotted lines using a moving average. The "dust-like" refractive index from Shettle and Fenn (1979), covering the entire spectrum of the radiative transfer model, is dashed black dashed.

the tropical AFGL standard atmosphere. Extrapolations towards the tropopause had to be performed to adjust the measured and standard profiles. The height of the tropopause on the day of the measurements was $17 \mathrm{~km}$, according to the temperature profile observed by a radiosonde launched at 06:00 UTC on 8 July 1997 from the island of Tenerife. The relative humidity, as observed by this radiosonde, has also been used as input for the model, see Fig. 2 .

Aerosol data: The measured size distributions of the dust's number concentration at the eight flight levels with the according altitudes (see Fig. 3) were assigned to model height levels. Size-averaged, size dependent as well as band averaged (Table 3) optical properties were calculated at these levels using Mie scattering theory and a certain spectral complex refractive index as basis for these calculations (Figs. 6, $7,8)$. For simulating the radiative transfer the measured aerosol size distributions were normalised with respect to the total number concentration of $1 \mathrm{~cm}^{-3}$, and the calculated normalised optical properties were linearly interpolated to the intermediate levels of the model atmosphere. Then, they were scaled by the measured total number concentration (Fig. 3) resulting, finally, in the spectral and height dependent scattering and absorption optical depth, the single scattering albedo as well as the asymmetry parameter.

Gas absorption: The tropical AFGL standard volume mixing ratio profile of ozone was replaced by the measured profile data (Fig. 2) in the lower atmosphere, and from the measured relative humidity a water vapour volume mixing ratio profile was computed. At higher altitudes the tropical AFGL standard profiles were used. 


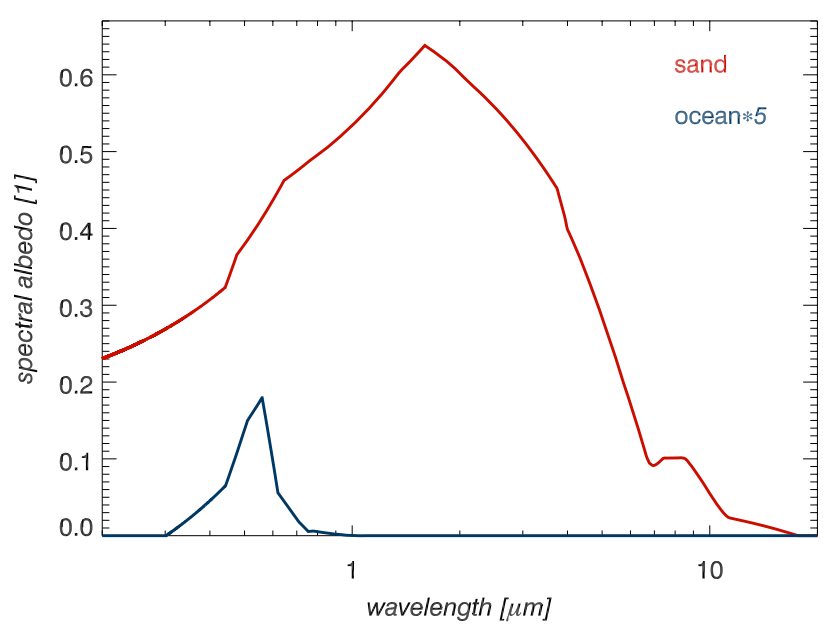

Fig. 5. Spectral surface albedo of desert (sand) and ocean. For clarity, the values for ocean were multiplied by a factor of 5 .

Spectral complex refractive index: Lafon et al. (2006) reported about the effect of the variability of the refractive index with respect to dust optical properties as well as that the single scattering albedo of mineral dust is significantly influenced by this quantity. Thus, one has to keep in mind the variabilities of the refractive index in literature data for mineral dust aerosols (dotted curves in Fig. 4) following Patterson et al. (1977), Carlson and Benjamin (1980), Sokolik et al. (1993) and Sokolik et al. (1998). Since no direct measurements of the refractive index were available from ACE-2, first, a mean real and imaginary part, see the two solid lines in Fig. 4, were extracted from a wide range of the literature data by applying a moving average leading to an imaginary part of 0.006 at $550 \mathrm{~nm}$ similar to 0.005 used by Formenti et al. (2000). Second, for sensitivity studies, maximum and minimum spectral real and imaginary parts of the refractive indices were calculated from these literature data as upper and lower envelope of the various curves. Third, the dustlike (black dashed graphs) refractive index following Shettle and Fenn (1979) based on Volz (1972) and Volz (1973) was used, since it is, contrary to the other cited data, defined over the entire wavelength range of the radiative transfer model from $200 \mathrm{~nm}$ to $39 \mu \mathrm{m}$.

Spectral surface albedo: The albedo of desert (sand) was taken from the MOSART database (http://eic.ipo.noaa. gov/IPOarchive/SCI/atbd/msoCD9FD.pdf) and the albedo of ocean from Schröder (2004). Both albedos are illustrated in Fig. 5 where, for better clarity, the albedo of the ocean surface has been multiplied by a factor of 5 .

3.3 Calculated quantities, reference cases and sensitivity studies

From the input parameters the following optical properties were calculated for the measured Saharan dust as function of altitude and wavelength: i) the scattering, absorption and extinction coefficients, ii) the single scattering albedo, iii) the asymmetry parameter of the scattering phase function and iv) the layer optical depths. These quantities will be analysed and interpreted in Sect. 4.1.

Since the airborne measurements were carried out over the Atlantic Ocean, one part of the simulations refers to the albedo of the ocean. However, as mentioned in the introduction, the underlying surface can have a significant influence on the radiation field in the dusty atmosphere. Therefore, two reference cases have been defined: the ocean and desert case. Both cases were defined for a cloudless tropical atmosphere including gas absorption, Rayleigh scattering and the measured dust particles as aerosols only. For the wavelength dependence of the real and imaginary parts of the complex index of refraction the moving average data (Fig. 4) have been chosen. Note that these two reference cases differ in the spectral albedo (Fig. 5) as well as in the emission temperature of the surface $\left(22^{\circ} \mathrm{C}\right.$ in the case of ocean, $35^{\circ} \mathrm{C}$ for desert). If the dust is entirely neglected in both cases, the atmosphere is referred as "clear sky". Unless otherwise noted, all simulations were performed for a solar zenith angle (SZA) of $0^{\circ}$ in order to obtain the maximum radiative effect. Thereby, the so-called atmospheric radiative effect (ARE) at TOA was calculated through

$\Delta F(\mathrm{TOA})=\int\left[F_{+}\left(z_{\mathrm{TOA}}, \lambda\right)-F_{+}^{r}\left(z_{\mathrm{TOA}}, \lambda\right)\right] d \lambda$

as well as at BOA following

$\Delta F(\mathrm{BOA})=\int\left[F_{-}\left(z_{\mathrm{BOA}}, \lambda\right)-F_{-}^{r}\left(z_{\mathrm{BOA}}, \lambda\right)\right] d \lambda$

in $\mathrm{Wm}^{-2}$ where $F_{+}(z, \lambda)$ and $F_{-}(z, \lambda)$, in $\mathrm{Wm}^{-2} \mathrm{~nm}^{-1}$, are the upward and downward irradiances of a considered scenario, which is compared to a references case (index r). The above spectral integrations in the Eqs. (2) and (3) were performed over the $\mathrm{SR}$ ( $\Delta F$ with index s) as well as LR (index l) and were summed to obtain the total effect (index t). While $\Delta F_{s, l, t}(\mathrm{TOA})$ characterises the radiation loss of the Earth-atmosphere system (EAS), the sum $\Delta F_{s, l, t}(A):=\Delta F_{s, l, t}(\mathrm{BOA})+\Delta F_{s, l, t}(\mathrm{TOA})$ describes this radiation deficit for the atmosphere only. Thus, $\Delta F_{s, l, t}(A)>0$ means a cooling and $<0$ a warming of the atmosphere.

With the help of the vertical shortwave, longwave as well as total radiative heating rates $h_{s, l, t}(z)$ of an individual scenario, from the Eq. (1) in Sect. 3.1, the deviation heating rates

$\Delta h_{s, l, t}(z)=h_{s, l, t}(z)-h_{s, l, t}^{r}(z)$

in units of $\mathrm{Kd}^{-1}$ were computed in comparison to the reference cases (r). 
In order to study the AREs of the in situ measured ACE-2 mineral dust the following scenarios have been considered compared to the two reference cases containing the dust:

1. Neglect the measured dust - in order to explore its pure optical effect.

2. Consider a tropospheric standard maritime aerosol in addition to the dust - in order to learn about the effects of a dusty atmosphere directly over the ocean or over desert but close to the coast.

3. Vary the total spectral optical depth of the dust - in order to simulate a lower or larger load of the measured dust particles.

4. Change the solar zenith angle - to demonstrate the diurnal variation of the impact of the dust.

5. Use different sets of spectral complex refractive indices compared to the spectral mean of Fig. 4 - due to the uncertainties with respect to this highly relevant quantity as indicated in this figure.

6. Neglect dust particles with diameters larger than $4 \mu \mathrm{m}$ in the measured size distributions - in order to work out especially the portion of the large particles of the dust on its radiative effect.

\section{Results}

In the following $\tau$ means the optical depth, $g$ the asymmetry parameter, $\omega_{o}$ the single scattering albedo and $n_{I}$ the imaginary part of the complex refractive index. In order to indicate their dependence on wavelength, its value in micrometres is added in parentheses, e.g. $\omega_{o}(0.55)$.

\subsection{Optical properties of the measured mineral dust}

In the lower part of the atmosphere during the ACE-2 campaign large particles $\left(D_{p}>4 \mu \mathrm{m}\right)$ were observed (see Fig. 3, levels 1-4). In Fig. 6 (top) one can recognise that these larger particles are characterised by a lower solar single scattering albedo: $\omega_{o}(0.55) \sim 0.76$ for the levels $2-4$ in the dust layer as compared to $\omega_{o}(0.55)$ up to $0.96(+26.3 \%)$ for the levels 5-8 where no large particles were present. This corresponds to the value of 0.73 measured during ACE-2 within the dust plume (Öström and Noone, 2000). Figure 6 (top) also demonstrates that scattering dominates the shortwave extinction, while there is mainly absorption in the longwave spectral range. This opposite behaviour is less pronounced, if large particles are present: They decrease the shortwave and increase the longwave scattering fraction, compare level 2/level 8 with/without these large particles.

Figure 6 (bottom) illustrates the size-averaged asymmetry parameter versus wavelength for all flight levels. One can see a primarily forward scattering in the shortwave range with

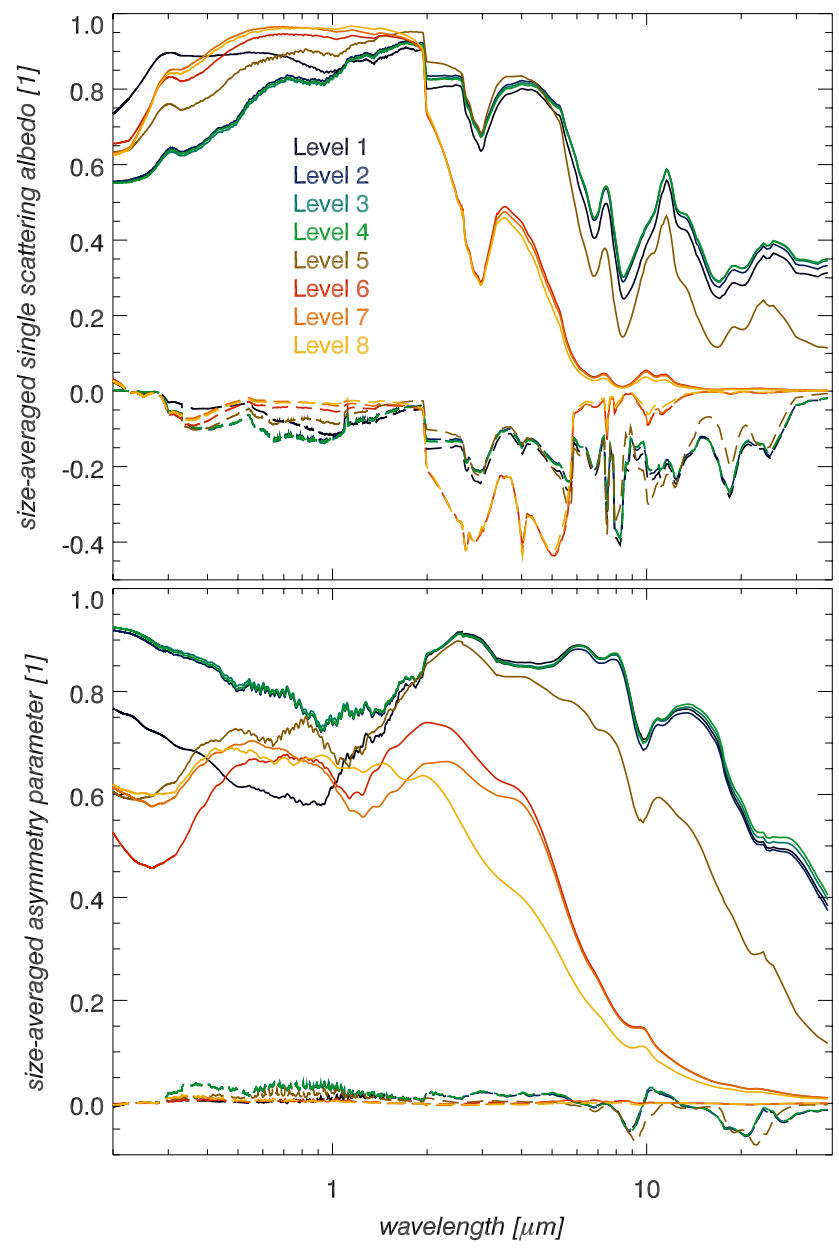

Fig. 6. Solid lines: Spectral size integrated single scattering albedo (top) and asymmetry parameter (bottom) at the eight flight levels derived from the measured size distributions for the mean complex refractive index (Fig. 4). Dashed lines: Difference of the solid lines for the mean imaginary part and the calculated curves for the minimum imaginary part (lower envelope of the dotted red lines in Fig. 4).

values up to $g(0.55) \sim 0.81$ for the levels $2-4$, while backward scattering becomes more dominant in the longwave spectral region. The levels 5-8 show lower values down to $g(0.55) \sim 0.65(-19.8 \%)$ due to the absence of the large particles. Further, the larger particles at the lower levels 2-4 increase $g$ in the entire spectral range but more dominant in the longwave.

In the marine boundary layer (level 1) there were both large particles and a higher fraction of particles with diameters $0.08<D_{p}<0.4 \mu \mathrm{m}$ resulting in a single scattering albedo $\omega_{o}(0.55) \sim 0.9$ and an asymmetry parameter $g(0.55) \sim 0.6$, which are larger and lower than in the levels $2-4$, respectively. That means that these optical properties depend significantly on the ratio of smaller and larger particles, which differed strongly with altitude. 

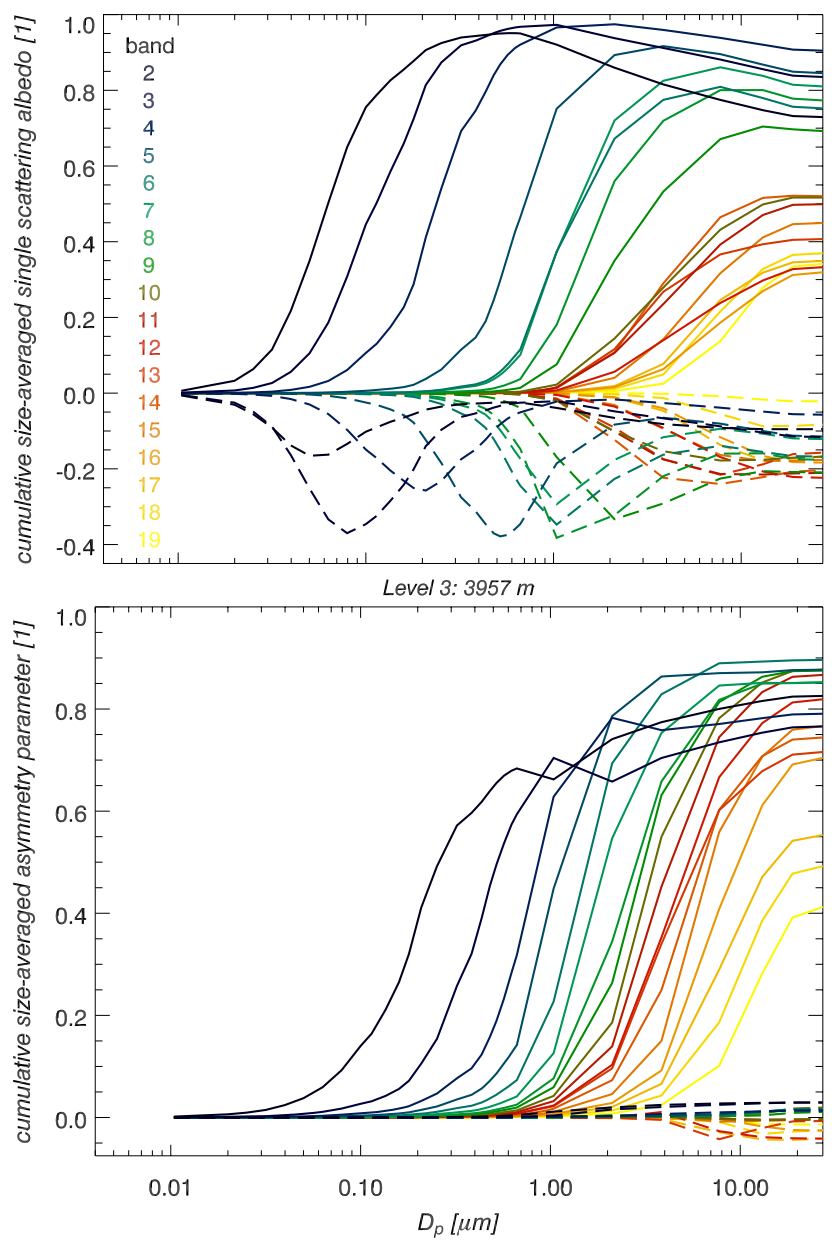

Fig. 7. Solid lines: Band averaged single scattering albedo (top) and asymmetry parameter (bottom) at flight level 3 within the dust plume, size integrated cumulatively up to the particle diameter $D_{p}$ using the mean complex refractive index shown in Fig. 4. Dashed lines: Difference of the solid lines for the mean imaginary part and the calculated curves for the minimum imaginary part (lower envelope of the dotted red lines in Fig. 4).

Figure 7 (top) and (bottom) illustrate the cumulative sizeaveraged single scattering albedo and asymmetry parameter as function of the particle diameter $D_{p}$ at the level 3 within the dust plume averaged over the spectral bands summarised in Table 3. Cumulative means that the size integration over the measured number size distributions considers all particles up to the diameter $D_{p}$, so that the contribution of respective particle sizes can be investigated. Both Figs. 7 indicate a significant influence of the large particles. They increase the asymmetry parameter and, thus, the forward scattering in the entire spectral range as well as the single scattering albedo in the longwave bands. In the shortwave bands they decrease the single scattering albedo: In band $2(0.2-0.7 \mu \mathrm{m})$ $\omega_{o}$ increases from a value of 0.73 , when taking into account the entire size distribution, up to $0.83(+13.7 \%)$, if particles with diameters below $3 \mu \mathrm{m}$ are considered. Hence, the coarse
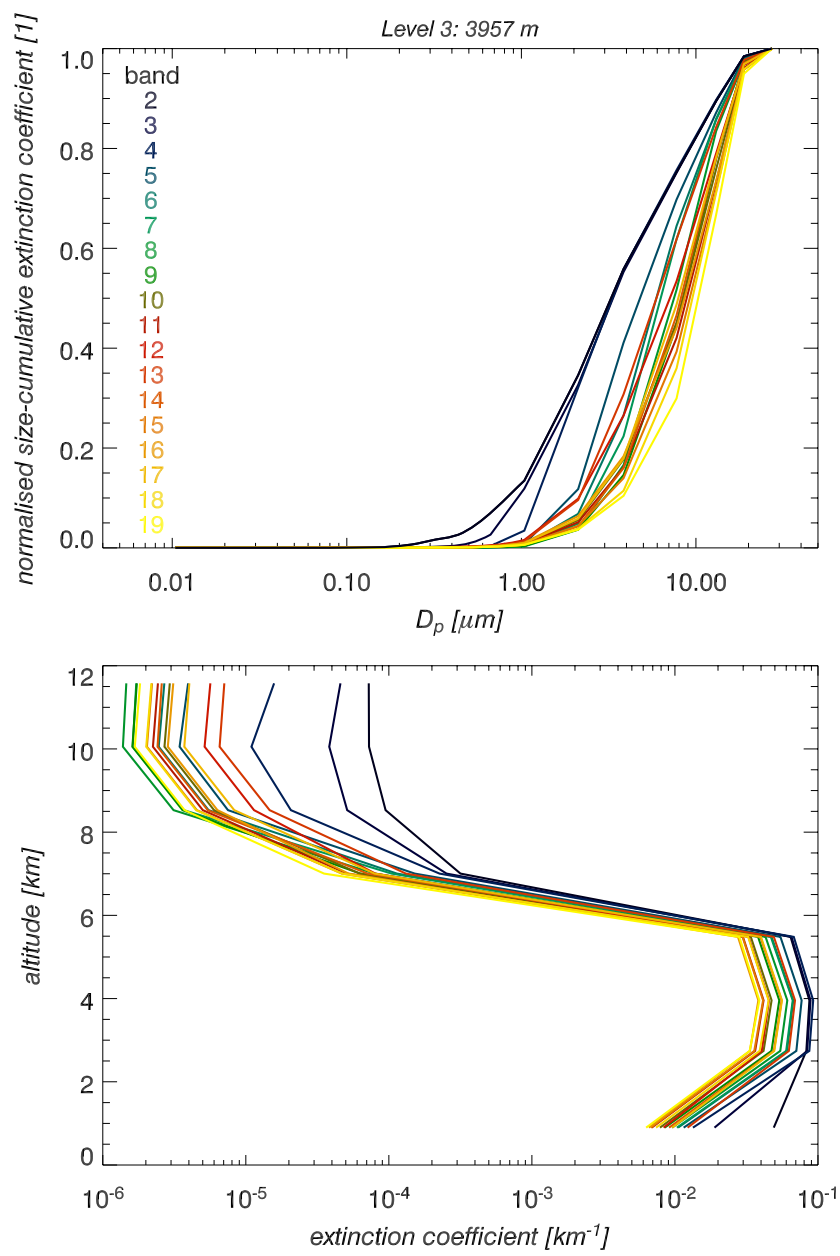

Fig. 8. (top) Size-cumulative band averaged extinction coefficient (analoguous to Fig. 7) normalised to the value of the largest diameter. (bottom) Size integrated extinction coefficient as function of the altitude.

mode particles can decrease/increase the shortwave single scattering albedo/asymmetry parameter as also reported by Defresne et al. (2002) and Wang et al. (2006). This is highly important for comparisons to values derived from scattering and absorption measurements (e.g. by nephelometer as well as absorption photometer, respectively), if the measurement system has a cut-off diameter of $\sim 3 \mu \mathrm{m}$ (Haywood et al., 2003) meaning that a significant fraction of optically efficient particles is lost.

There is also a significant uncertainty with respect to the imaginary part of the complex refractive index (Fig. 4). The previous calculations were performed for the mean imaginary part (red solid curve) with $n_{I}(0.55)=0.0063$. The same computations were made for the lower envelope of all red dotted literature data leading to $n_{I}(0.55)=0.0033$. The resulting single scattering albedo as well as asymmetry parameter were subtracted from the calculated values for the mean imaginary part, and these differences were plotted as 


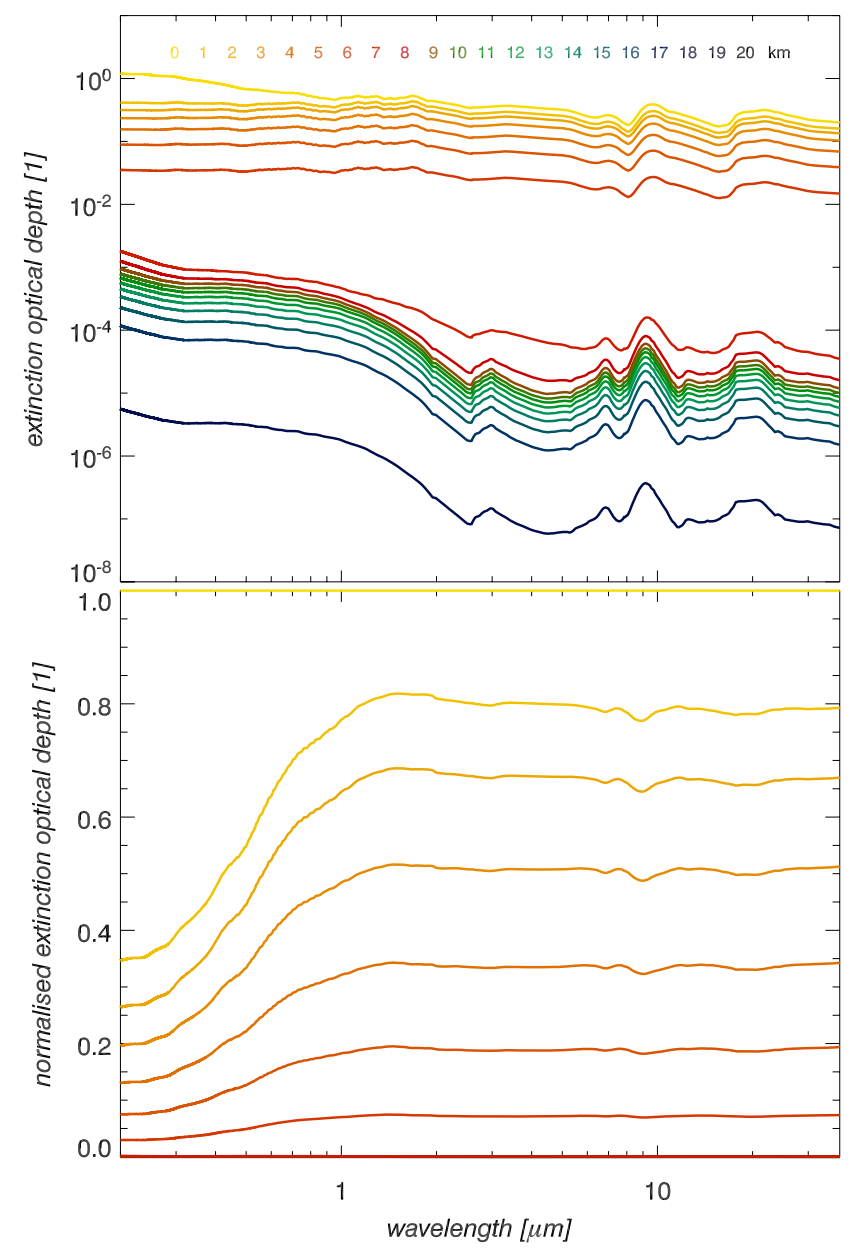

Fig. 9. Spectral dust extinction optical depth calculated from the measured size distributions for the mean complex refractive index in Fig. 4. (top) As function of the altitude at the model levels $0-20 \mathrm{~km}$. (bottom) As in the top plot but normalised to the value at surface level $(0 \mathrm{~km})$.

dashed curves in the Figs. 6 and 7. These four figures demonstrate that the asymmetry parameter is less sensitive to the decrease of the imaginary part compared to the single scattering albedo. In the shortwave range the single scattering albedo increased by up to 0.15 (Fig. 6, top), while the asymmetry parameter only decreased by up to 0.05 (Fig. 6, bottom). Thereby, $\omega_{o}(0.55)$ rises from 0.76 to $0.84(+10.5 \%)$ and $g(0.55)$ declines from 0.81 to $0.79(-2.5 \%)$ for the dust aerosol. In the longwave range the changes in the optical properties are larger with $\left|\Delta \omega_{o}\right|<0.45$ as well as $|\Delta g|<0.1$ and significant differences in the various flight levels. In the Figs. 7 (top) and (bottom) the variations of the size cumulative optical properties of the measured dust due to the lower imaginary part of the refractive index are shown for the different spectral bands as dashed curves. For band 2 and a particle diameter of $3 \mu \mathrm{m}$ the single scattering albedo/asymmetry parameter increases/decreases from $0.83 / 0.76$ to $0.91 / 0.74(+9.6 /-2.6 \%)$. Even lower values of the imaginary parts, e.g. suggested by Haywood et al. (2003) with $n_{I}(0.55)=0.0015$, can produce even larger values for the single scattering albedo and lower values for the asymmetry parameter.

The significant influence of large particles on the extinction can be seen in Fig. 8 (top) showing the cumulatively size integrated extinction coefficient averaged over the spectral bands of Table 3 for flight level 3 as function of the particle diameter $D_{p}$. In addition, the curves have been normalised to the maximum observed particle size to obtain a function between 0 and 1 , from which one can read off the portion of the respective diameter on the extinction coefficient in percent: Particles larger than $3 \mu \mathrm{m}$ contribute up to $50 \%$ in the shortwave and $90 \%$ in the longwave bands. Note that the maximum of extinction is observed in the dust layer (levels 2-4), see Fig. 8 (bottom), and the extinction is most dominant in the shortwave bands 2-6.

Figure 9 (top) illustrates the spectral dust extinction optical depth as a function of the altitude. In the longwave the largest contributions are caused by layers below $7 \mathrm{~km}$, e.g. inside the dust plume with the maximum extinction occurring at $4 \mathrm{~km}$ altitude (Fig. 8, bottom). For the UV wavelengths the lowermost $1 \mathrm{~km}$ thick atmospheric layer contributes as much as $65 \%$ to the total optical depth (Fig. 9, bottom). This is due to the high number concentration at level 1 at $900 \mathrm{~m}$ altitude (Fig. 3), which has been adopted for all model layers below. The calculated total dust optical depth was computed with values of $\tau(0.2)=1.18$ and $\tau(0.55)=0.66$. These simulated optical depths will be compared in the following with independent measurements performed during ACE-2:

- The dust optical depth was measured during ACE-2 on the slope of the volcano "El Teide" at $3570 \mathrm{~m}$ (comparable to flight level 3 of the present work) using a sun photometer (Formenti et al., 2000) leading to a mean optical depth of $\tau(0.5)=0.136 \pm 0.01$ on 8 July. Model calculations using the airborne measured size distributions yield a value of $\tau(0.5)=0.179$ at $3600 \mathrm{~m}$, which is in agreement with the sun photometer data within the expected uncertainties, e.g., that airborne and groundbased measurements were performed at different geographical locations.

- Considering the entire dust column from the surface to the $11.6 \mathrm{~km}$, Smirnov et al. (1998) derived $\tau(0.5)$ of $0.37 \pm 0.04$ for the averaged total optical depth. The ACE-2 airborne size distributions yield $\tau(0.5)=0.31$ for the dust plume extending between 0.9 and $5.5 \mathrm{~km}$. From the aircraft observations at $900 \mathrm{~m}$ it is concluded that (see Fig. 2) a second large particle dust plume existed below this particular altitude. Since no in situ particle measurements were made, the size distribution data have been extrapolated homogenously for altitudes below the $900 \mathrm{~m}$ level. In this manner one obtains $\tau(0.55)=0.66$ representing a scenario as it may be observed closer to the Saharan source regions. 


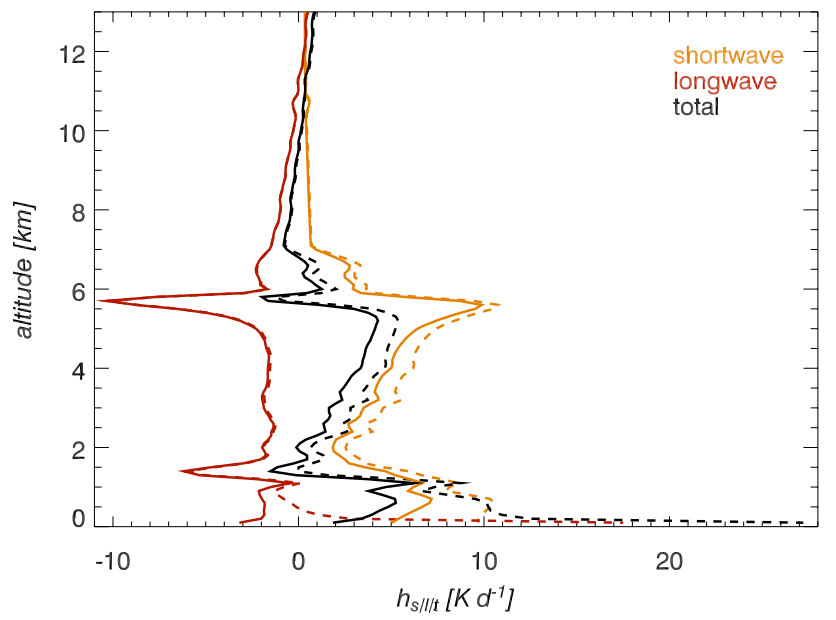

Fig. 10. Profiles of the shortwave, longwave as well as total radiative heating rates for the reference case: measured ACE-2 dust over ocean (solid) and desert (dashed).

Formenti et al. (2000) retrieved monomodal size distributions between the diameter bounds 2 and $20 \mu \mathrm{m}$ from spectral optical depths measured by sun photometers on 8 July on El Teide. Assuming the complex refractive index of $1.55-0.005 i$ they found $\omega_{o}(0.5)=0.87 \pm 0.29$ and $g(0.5)=0.73 \pm 0.15$ confirming the values computed above.

\subsection{The AREs of the measured mineral dust plume}

In the following the sensitivity studies 1-6 are investigated as defined in Sect. 3.3. The corresponding AREs calculated at TOA as well as BOA over ocean and desert are listed in Table 4 and discussed in the Sects. 4.2.1 to 4.2.6.

Figure 10 shows the shortwave, longwave as well as total heating rates for the two reference cases ocean and desert. The heating in the shortwave and cooling in the longwave region lead to a positive total heating inside the dust plume and in the lowest kilometre of the atmosphere. Due to the higher surface albedo over the desert the solar heating increases weakly above the altitude of $1 \mathrm{~km}$ and strongly below. The longwave radiative flux divergence is mainly affected in the lower troposphere below the altitude of $1 \mathrm{~km}$ with a significant positive heating close to the surface. Here, the longwave cooling over ocean turns into a heating over desert.

From the previous profiles of the reference heating rates the deviation heating rates $\Delta h_{s, l, t}(z)$, see the Eqs. (1) and (4), were calculated over ocean (solid) and desert (dashed) within the scope of the sensitivity studies $1-6$ and are presented in the Figs. 11 to 15.

Note that the profiles presented in the Figs. 10 to 15 exhibit a certain degree of vertical structure. This can be traced back to the variabilities in the input data (Figs. 2 and 3).

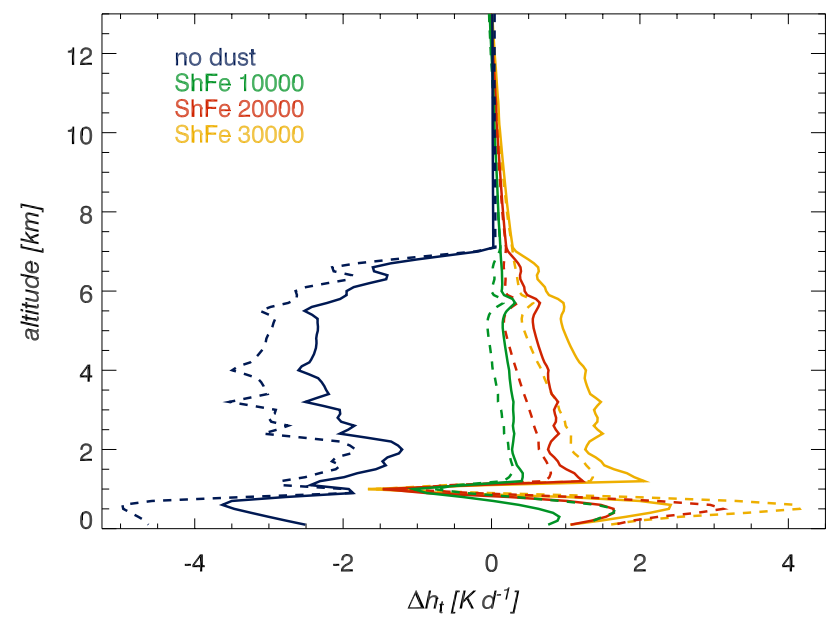

Fig. 11. Profiles of the deviation from the total radiative heating rates of the reference cases ocean (solid) as well as desert (dashed), $\Delta h_{t}(z)$, if the measured dust is neglected completely (no dust) or a standard tropospheric aerosol of Shettle and Fenn (1979) is added with surface number concentrations 10000, 20000 and $30000 \mathrm{~cm}^{-3}(\mathrm{ShFe} 10000 / 20000 / 30000)$.

\subsubsection{Radiative effect of the measured dust}

This scenario neglects the measured mineral dust totally. The simulations yield a negative $\Delta h_{t}$ due to reduced absorption as follows from the curve "no dust" in Fig. 11. This effect is stronger in the desert case, since a higher amount of radiation reflected from the surface is not absorbed, and the behaviour corresponds to the calculated AREs at the bottom and top of the atmosphere, see Table 4 and sensitivity study 1: The neglected dust gives rise to an increased ARE at BOA due to reduced absorption, with a larger value of $\Delta F_{t}(\mathrm{BOA})$ over ocean $\left(+202 \mathrm{~W} \mathrm{~m}^{-2}\right)$ than over the desert $\left(+160 \mathrm{~W} \mathrm{~m}^{-2}\right)$. However, the behaviour at the TOA is quite different over the two surfaces: A negative total ARE with $\Delta F_{t}(\mathrm{TOA})=-53 \mathrm{~W} \mathrm{~m}^{-2}$ was computed over the ocean, since the reflecting dust is not present, but a positive value $+107 \mathrm{~W} \mathrm{~m}^{-2}$ over the desert due to the lack of the absorbing dust. This means a total radiative cooling/warming of the EAS in the case of the dusty atmosphere over the ocean/desert surface. These values are similar to Quijano et al. (2000a), Haywood et al. (2001) and Myhre et al. (2003). Considering the atmosphere only, the dust always produces a warming due to $\Delta F_{t}(A)=-149 /-267 \mathrm{~W} \mathrm{~m}^{-2}$.

$\Delta F_{l}(\mathrm{BOA} / \mathrm{TOA})$ indicate that the dust heats/cools the atmosphere below/above the dust layer in the longwave.

\subsubsection{Presence of an additional standard maritime aerosol}

Figure 11 presents the influence of an additional standard oceanic aerosol after Shettle and Fenn (1979) on the radiative heating of the dusty atmosphere. Its total number concentration is assumed to decrease exponentially with 
Table 4. Atmospheric radiative effects (AREs) $\Delta F=F-F^{r}$ for the sensitivity studies $1-6$ where the $F$ 's are the spectrally integrated upward $(+)$ /downward (-) flux densities at TOA/BOA (upper/lower values) in $\mathrm{W} \mathrm{m}^{-2}$ after the Eqs. (2) and (3). The reference cases (r) are defined as the clear sky atmospheres over ocean (surface temperature $T_{s}=22^{\circ} \mathrm{C}$ ) and desert $\left(35^{\circ} \mathrm{C}\right)$ containing the measured dust.

\begin{tabular}{|c|c|c|c|c|c|c|c|}
\hline & \multicolumn{3}{|c|}{ Ocean } & \multicolumn{3}{|c|}{ Desert } \\
\hline & & $S R$ & $L R$ & Total & $S R$ & $L R$ & Total \\
\hline & $F_{+}^{r}(\mathrm{TOA})$ & 121.1 & 259.3 & 380.4 & 378.2 & 269.0 & 647.2 \\
\hline & $F_{-}^{r}(\mathrm{BOA})$ & 866.2 & 333.8 & 1200.0 & 934.7 & 334.3 & 1269.1 \\
\hline \multicolumn{2}{|r|}{ Sensitivity study (i) } & \multicolumn{3}{|c|}{ AREs $\Delta F_{s, l, t}(\mathrm{BOA} / \mathrm{TOA})$} & \multicolumn{3}{|c|}{ AREs $\Delta F_{s, l, t}(\mathrm{BOA} / \mathrm{TOA})$} \\
\hline \multirow[t]{2}{*}{ (1) } & no dust & -60.9 & +7.6 & -53.4 & +96.7 & +10.2 & +106.9 \\
\hline & 110 dust & +217.6 & -15.7 & +202.0 & +176.1 & -16.2 & +159.9 \\
\hline \multirow[t]{6}{*}{ (2) } & ShFe 10000 & +32.4 & -3.5 & +28.9 & -9.5 & -5.9 & -15.5 \\
\hline & 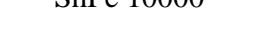 & -65.2 & +14.0 & -51.1 & -38.1 & +14.1 & -24.0 \\
\hline & ShFe 20000 & +94.2 & -5.1 & +89.1 & +2.9 & -9.4 & -6.5 \\
\hline & गIITE 20000 & -173.1 & +24.3 & -148.8 & -125.7 & +24.6 & -101.1 \\
\hline & ShFe 30000 & +145.9 & -6.3 & +139.6 & +17.4 & -12.0 & +5.4 \\
\hline & & -265.9 & +31.6 & -234.3 & -210.5 & +32.1 & -178.4 \\
\hline \multirow[t]{12}{*}{ (3) } & $\tau(0.55)=0.25$ & -31.4 & +4.3 & -27.0 & +54.9 & +5.9 & +60.8 \\
\hline & $(0.53)-0.25$ & +129.6 & -9.0 & +120.5 & +109.8 & -9.3 & +100.4 \\
\hline & $\tau(0.55)=0.5$ & -10.3 & +1.6 & -8.7 & +19.6 & +2.3 & +21.7 \\
\hline & $(0.00)-0.0$ & +48.1 & -3.3 & +44.8 & +42.2 & -3.4 & +38.8 \\
\hline & $\tau(0.55)=1.0$ & +16.4 & -3.0 & +13.4 & -36.9 & -4.2 & -41.1 \\
\hline & $0(0.00)-1.0$ & -96.2 & +6.3 & -89.9 & -88.5 & +6.5 & -81.9 \\
\hline & $\tau(0.55)=1.32$ & +26.3 & -5.5 & +20.8 & -65.4 & -7.5 & -73.0 \\
\hline & $4(0.07)-1.02$ & -175.4 & +11.4 & -164.1 & -164.9 & +11.8 & -153.2 \\
\hline & $\tau(0.55)=2.0$ & +36.8 & -10.0 & +26.8 & -113.9 & -13.8 & -127.6 \\
\hline & $4(0.007)-2.0$ & -320.5 & +20.3 & -300.2 & -311.9 & +21.1 & -290.9 \\
\hline & $\tau(0.55)=50$ & +28.4 & -23.3 & +5.1 & -211.3 & -30.9 & -242.2 \\
\hline & $(0.00)-3.0$ & -668.2 & +41.4 & -626.8 & -695.6 & +43.2 & -652.4 \\
\hline \multirow[t]{12}{*}{ (4) } & $S Z A=10^{\circ}$ & -0.25 & -0.00 & -0.25 & -5.4 & -0.01 & -5.4 \\
\hline & $S Z A-10$ & -18.1 & -0.07 & -18.2 & -19.5 & -0.07 & -19.6 \\
\hline & $S Z A=20^{\circ}$ & -1.02 & -0.00 & -1.02 & -21.4 & -0.04 & -21.4 \\
\hline & $5 \angle A=\angle U$ & -71.5 & -0.26 & -71.8 & -77.1 & -0.27 & -77.4 \\
\hline & $S Z A=30^{\circ}$ & -2.4 & -0.01 & -2.4 & -47.3 & -0.08 & -47.4 \\
\hline & $52 \pi-50$ & -157.6 & -0.57 & -158.2 & -169.9 & -0.58 & -170.5 \\
\hline & $S Z A=40^{\circ}$ & -4.5 & +0.00 & -4.5 & -82.4 & -0.14 & -82.5 \\
\hline & & -271.8 & -0.97 & -272.8 & -293.1 & -0.99 & -294.1 \\
\hline & $S Z A=50^{\circ}$ & -8.2 & +0.01 & -8.1 & -125.4 & -0.19 & -125.6 \\
\hline & $52 \pi-50$ & -407.2 & -1.43 & -408.7 & -439.2 & -1.45 & -440.6 \\
\hline & $S Z A=60^{\circ}$ & -14.9 & +0.02 & -14.9 & -175.6 & -0.27 & -175.8 \\
\hline & & -553.9 & -1.90 & -555.8 & -597.4 & -1.93 & -599.4 \\
\hline \multirow[t]{10}{*}{ (5) } & $\min (i m)-\min (r e)$ & +20.8 & +4.6 & +25.3 & +56.3 & +6.2 & +62.5 \\
\hline & & +41.7 & -9.0 & +32.8 & +56.9 & -9.3 & +47.6 \\
\hline & $\min (i m)-\max (r e)$ & +21.1 & -3.0 & +18.1 & +56.2 & -2.7 & +53.5 \\
\hline & & +41.0 & -0.66 & +40.4 & +56.4 & +0.01 & +56.4 \\
\hline & $\max (i m)-\min (r e)$ & -15.3 & -0.83 & -16.1 & -41.6 & -1.6 & -43.1 \\
\hline & & -34.9 & +4.5 & -30.4 & -46.4 & +4.4 & -42.0 \\
\hline & $\max (i m)-\max (r e)$ & -15.2 & -3.0 & -18.2 & -41.8 & -4.0 & -45.8 \\
\hline & & -35.6 & +5.1 & -30.5 & -46.9 & +5.3 & -41.7 \\
\hline & dust-like & -3.1 & -0.57 & -3.7 & -13.3 & -0.27 & -13.6 \\
\hline & & -8.8 & -1.6 & -10.4 & -12.2 & -1.3 & -13.5 \\
\hline \multirow[t]{2}{*}{ (6) } & no large particles & +5.0 & +5.3 & +10.3 & +64.3 & +7.0 & +71.4 \\
\hline & 10 rarge particies & +80.2 & -9.8 & +70.4 & +81.9 & -10.3 & +71.6 \\
\hline
\end{tabular}




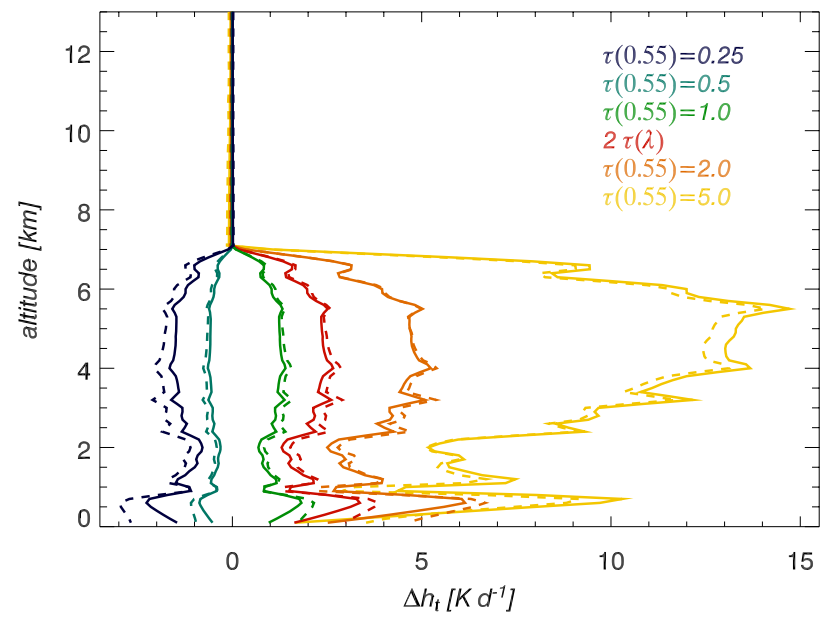

Fig. 12. Profiles of the deviation from the total radiative heating rates of the reference cases ocean (solid) as well as desert (dashed), $\Delta h_{t}(z)$, as function of the scaled measured dust optical depth.

increasing altitude (see Fig. 3 and compare it to the measured number concentration of the Saharan mineral dust) and is varied through the surface values of 10000,20000 and $30000 \mathrm{~cm}^{-3}$. These aerosols, mainly containing particles $<1 \mu \mathrm{m}$, are added to the observed dust leading to a positive radiative heating due to the increase of the total aerosol optical depth (Fig. 11). The values of $\Delta F_{t}(A)$ calculated from Table 4 (sensitivity study 2 ) are always negative affirming this atmospheric warming effect, which is stronger over the reflecting desert and increases with the number concentration of the standard aerosol.

The maritime aerosol particles scatters strongly resulting in enhanced multiple scattering (backscattering) but also leading to increased total absorption by the combined aerosol. Thus, less radiation reaches the Earth's surface with $\Delta F_{t}(\mathrm{BOA})<0$ but more the top of the atmosphere: $\Delta F_{t}(\mathrm{TOA})$ exhibits positive values over ocean, indicating a cooling of the EAS being larger, the more the surface number concentration of the oceanic aerosol is increased. Over desert the warming impact $\left(\Delta F_{t}(\mathrm{TOA})=-15.5\right)$ turns into a cooling $(+5.4)$ when raising the load of the backscattering standard aerosol.

\subsubsection{Dusty atmosphere by varying the spectral total dust optical depth}

The total load of the measured dust is varied by scaling the originally calculated total optical depth $\tau(\lambda)$ to the values $\tau_{\text {new }}(0.55)=0.25 / 0.5 / 1.0 / 2.0 / 5.0$ and $\tau_{\text {new }}(\lambda)=2 \tau(\lambda)$ with $\tau_{\text {new }}(0.55)=1.32$. These cases of weaker and stronger dust loads than observed during ACE-2 resulting in $\Delta h_{t}$ 's as displayed in Fig. 12. In comparison to the reference cases, a larger optical depth causes enhanced positive total heating due to increased absorption, and the relative increase as well as decrease of $\Delta h_{t}$ is approximately equal for ocean

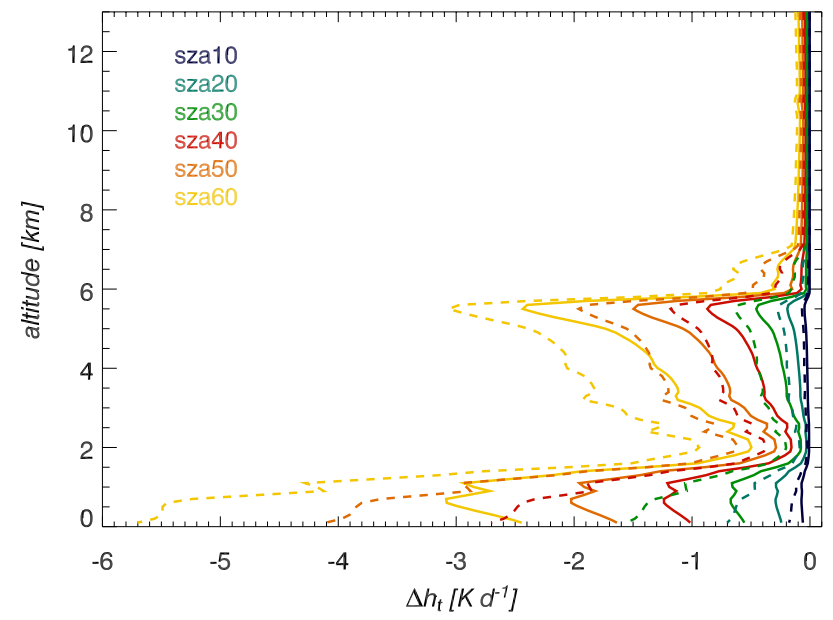

Fig. 13. Profiles of the deviation from the total radiative heating rates of the reference cases ocean (solid) as well as desert (dashed), $\Delta h_{t}(z)$, for various solar zenith angles between $10^{\circ}$ and $60^{\circ}$.

and desert. However, the changes in the shortwave irradiances at TOA are different. Table 4 (sensitivity study 3 ) shows that the total upward radiation at TOA increases with larger total optical depths over ocean but decreases strongly over desert, since mainly solar radiation, reflected from the surface, is multiply scattered and absorbed within the dust in the latter case. Moreover, in the ocean case this behaviour is only observed up to a certain value of the optical depth. For larger values the reflected radiation at TOA decreases again, consider the value $\Delta F_{t}(\mathrm{TOA})=+5 \mathrm{~W} \mathrm{~m}^{-2}$ in the case of " $\tau(0.55)=5.0$ ", which is substantially lower than the $+27 \mathrm{~W} \mathrm{~m}^{-2}$ for the lower optical depth " $\tau(0.55)=2.0$ ". The reason for this behaviour is that a larger total optical depth also gives rise to enhanced scattering and, thus, longer multiple scattering paths, along which radiation is absorbed. This effect has also been reported by Quijano et al. (2000a).

\subsubsection{Influence of the solar zenith angle}

An increase in the SZA has two opposite radiative effects within the atmosphere. On the one hand, the optical path of the direct solar light through the atmosphere increases, so that relatively increasing absorption is expected. On the other hand, this incident solar radiation decreases absolutely with increasing SZA. The resulting total radiative effect is negative. This cooling is shown in Fig. 13 representing the influence of the SZAs between $10^{\circ}$ and $60^{\circ}$.

Since the radiative transfer model deals with two source terms in the entire wavelength range, the solar spectrum also contributes to all longwave integrations, see the Eqs. (2) and (3). Therefore, the values of $\Delta F_{l}(\mathrm{BOA})$ and $\Delta F_{l}(\mathrm{TOA})$ in Table 4 (sensitivity study 4 ) show small changes in the longwave radiative transfer for the various SZA for both ocean and desert, however, the solar radiative transfer plays the decisive role. Table 4 indicates that less upward/downward 


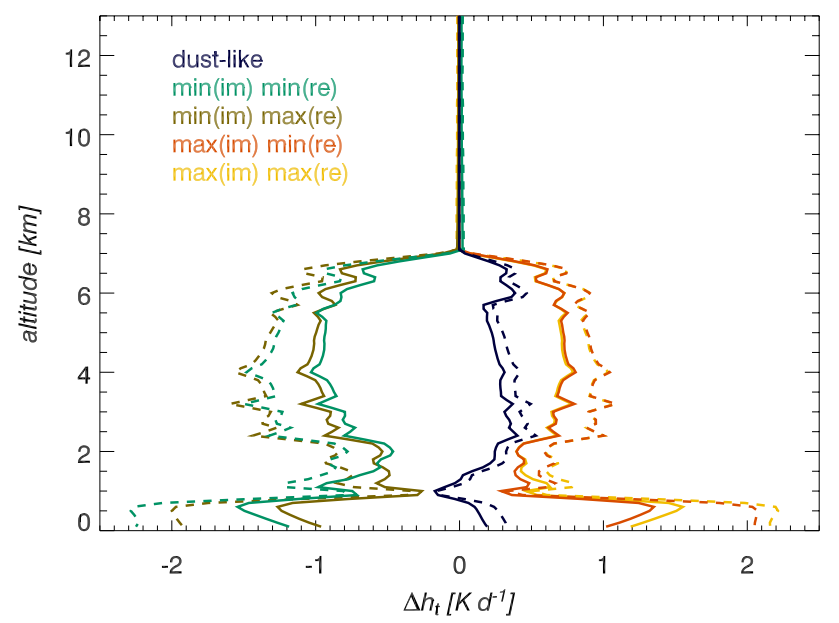

Fig. 14. Profiles of the deviation from the total radiative heating rates of the reference cases ocean (solid) as well as desert (dashed), $\Delta h_{t}(z)$, as function of the complex refractive index.

total radiation is observed at TOA/BOA relative to the reference cases for increasing SZA due to less incident radiation. Further, one can recognise significant higher negative values of the $\Delta F_{t}$ (TOA) over the desert compared to the ocean. This emphasises the warming effect of the dust aerosols over the desert.

\subsubsection{Effect of the spectral complex refractive index}

The dotted curves in Fig. 4 illustrate the uncertainties in the complex refractive index of mineral dust. Therefore, maximum and minimum spectral real as well as imaginary parts of the literature data (dotted curves) were considered in all their combinations to compute AREs and heating rates. In addition, the "dust-like" complex refractive index (black dashed) following Shettle and Fenn (1979) was used, since this is the only source of data, which covers the entire spectral wavelength range considered in this study.

The results of the $\Delta h_{t}$ simulations (Fig. 14) demonstrate that the imaginary part has the more significant effect to the total radiative heating. Smaller values of the imaginary part cause less absorption and, thus, a reduced heating and vice versa. When a higher fraction of larger particles is present (between 2 and $7 \mathrm{~km}$ altitude), an increase of the real part leads to a lower heating. However, for higher fractions of small particles (below $2 \mathrm{~km}$ altitude), a higher real part yields a positive contribution to the radiative heating. The "dustlike" refractive index results in a larger heating.

Table 4 (sensitivity study 5) shows the significant influence on the ARE, which the complex refractive index can have. A lower imaginary part causes a higher atmospheric radiative cooling of the EAS with positive $\Delta F_{t}$ (TOA) and vice versa. This behaviour is quite stronger over the desert compared to the ocean simulations.

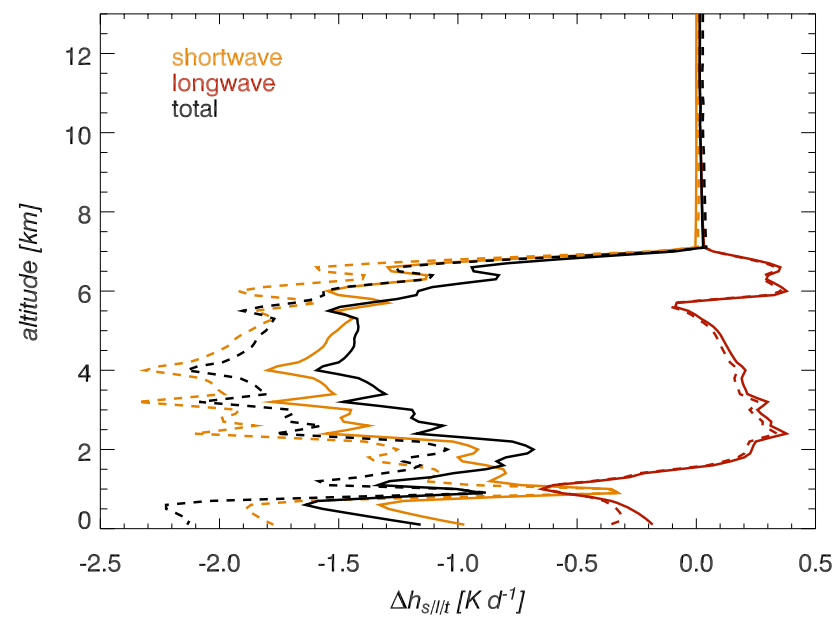

Fig. 15. Profiles of the deviation from the shortwave, longwave and total radiative heating rates of the reference cases ocean (solid) and desert (dashed), $\Delta h_{s, l, t}(z)$, if the large dust particles with diameters larger than $4 \mu \mathrm{m}$ are neglected.

\subsubsection{Absence of the large dust particles}

The influence of the large particles on the radiative transfer is investigated separately in this subsection. To do this all particles in the measured size distributions having diameters larger than $4 \mu \mathrm{m}$ were neglected. The re-computed optical properties are expected to show decreased forward scattering as well as absorption and, hence, less extinction. This leads to a significantly reduced total heating as the simulations of the deviation heating rates in Fig. 15 demonstrate. For the reference cases (Fig. 10) the values of the total heating rates at $5 \mathrm{~km}$ altitude are $+4.0 /+5.0 \mathrm{~K} \mathrm{~d}^{-1}$ over ocean/desert. When neglecting the large particles (Fig. 15), the heating rate is reduced to about $+2.6 /+3.2 \mathrm{~K} \mathrm{~d}^{-1}$. Hence, these particles contribute with $35 / 36 \%$ to the dust plume's total heating rate. Figure 15 also shows that the radiative heating is mainly determined by absorption properties of the large particles in the shortwave.

In order to calculate the contribution of the large particles to the total ARE at the TOA over the ocean/desert, firstly consider sensitivity study 1 representing the AREs of the entire dust in comparison to the dustless atmosphere with absolute values $\mid \Delta F_{t}^{\text {dust }}$ (TOA) $\mid$ of $53 / 107 \mathrm{~W} \mathrm{~m}^{-2}$ (Table 4). Starting from the reference case simulations, including all measured particles, one obtains $\Delta F_{t}^{\text {nolarge }}$ (TOA) of $10 / 71 \mathrm{~W} \mathrm{~m}^{-2}$ when neglecting the large particles (sensitivity study 6 in Table 4 ). Thus, the fraction

$\frac{\Delta F_{t}^{\text {no large }}(\text { TOA })}{\left|\Delta F_{t}^{\text {dust }}(\mathrm{TOA})\right|} \cdot 100 \%=19 / 67 \%$

yields the contribution of these particles to the ARE of the entire measured dust over ocean/desert. Although their number concentration is up to three orders of magnitude smaller than of the sub-microns (Fig. 2), they contribute at 
Table 5. Modal parameters of a bimodal column volume size distribution derived from the ACE-2 measured number size distributions according the Eqs. (5) for the large particle dust column from $0.9-5.5 \mathrm{~km}$ (see Fig. 3).

\begin{tabular}{ccc}
\hline & Fine mode $(\mathrm{i}=1)$ & Coarse mode $(\mathrm{i}=2)$ \\
\hline$D_{p, i}[\mu \mathrm{m}]$ & 0.54 & 9.45 \\
$C_{i}\left[\mu \mathrm{m}^{3} \mu \mathrm{m}^{-2}\right]$ & 0.01 & 0.55 \\
$\sigma_{i}[1]$ & 0.73 & 0.67 \\
\hline
\end{tabular}

least $\sim 20 \%$ to the ARE at TOA. The large particles always cause a total warming of the EAS, since they absorb radiation, which can not be transmitted to the TOA. Within the atmosphere only, they always result in a warming due to $\Delta F_{t}(A)=-81 /-143 \mathrm{~W} \mathrm{~m}^{-2}$ over ocean/desert (Table 4 ).

\subsection{The role of large mineral dust particles}

Ground and satellite based remote sensing instruments detect radiation transported through atmospheric columns, so that such measurements represent the vertically integrated state of the atmosphere containing gases, clouds and aerosols. These components differ in their individual volume fractions. From the ACE-2 measured size-bin-resolved number size distributions a column integrated bimodal volume size distribution $V_{c}\left(\ln D_{p}\right)$, having a fine $\left(I_{1}: D_{p}<1.2 \mu \mathrm{m}\right)$ and a coarse $\left(I_{2}: D_{p}>1.2 \mu \mathrm{m}\right)$ particle mode, was derived with modal parameters defined through

$$
\begin{aligned}
C_{i} & =\int_{I_{i}} V_{c}\left(\ln D_{p}\right) d \ln D_{p} \\
\ln D_{p, i} & =\frac{1}{C_{i}} \int_{I_{i}} \ln D_{p} V_{c}\left(\ln D_{p}\right) d \ln D_{p} \\
\sigma_{i} & =\sqrt{\frac{1}{C_{i}} \int_{I_{i}}\left(\ln D_{p}-\ln D_{p, i}\right)^{2} V_{c}\left(\ln D_{p}\right) d \ln D_{p}}
\end{aligned}
$$

in order to express $V_{c}$ analytically as

$V_{c}\left(\ln D_{p}\right)=\sum_{i=1}^{2} \frac{C_{i}}{\sqrt{2 \pi} \sigma_{i}} \exp \left[\frac{\left(\ln D_{p}-\ln D_{p, i}\right)^{2}}{2 \sigma_{i}^{2}}\right]$

The modal parameters for the large particle dust column from $0.9-5.5 \mathrm{~km}$ (Fig. 3) are listed in Table 5. To explore the role of the large particles for the atmospheric radiative effect (ARE) over ocean and desert, the data were used as follows. Consider homogeneous dust layers in this altitude range with realisticly varied coarse mode median diameters $D_{p, 2}$ by shifting it to smaller values, from $D_{p, 2}=9.45 \mu \mathrm{m}$ of the original ACE-2 dust plume (ACED) to diameters of 2.0, 4.0 and $8.0 \mu \mathrm{m}$ (cases ACEDI to ACEDIII) assuming constant standard deviations $\sigma_{i}$ and that the total particle volume

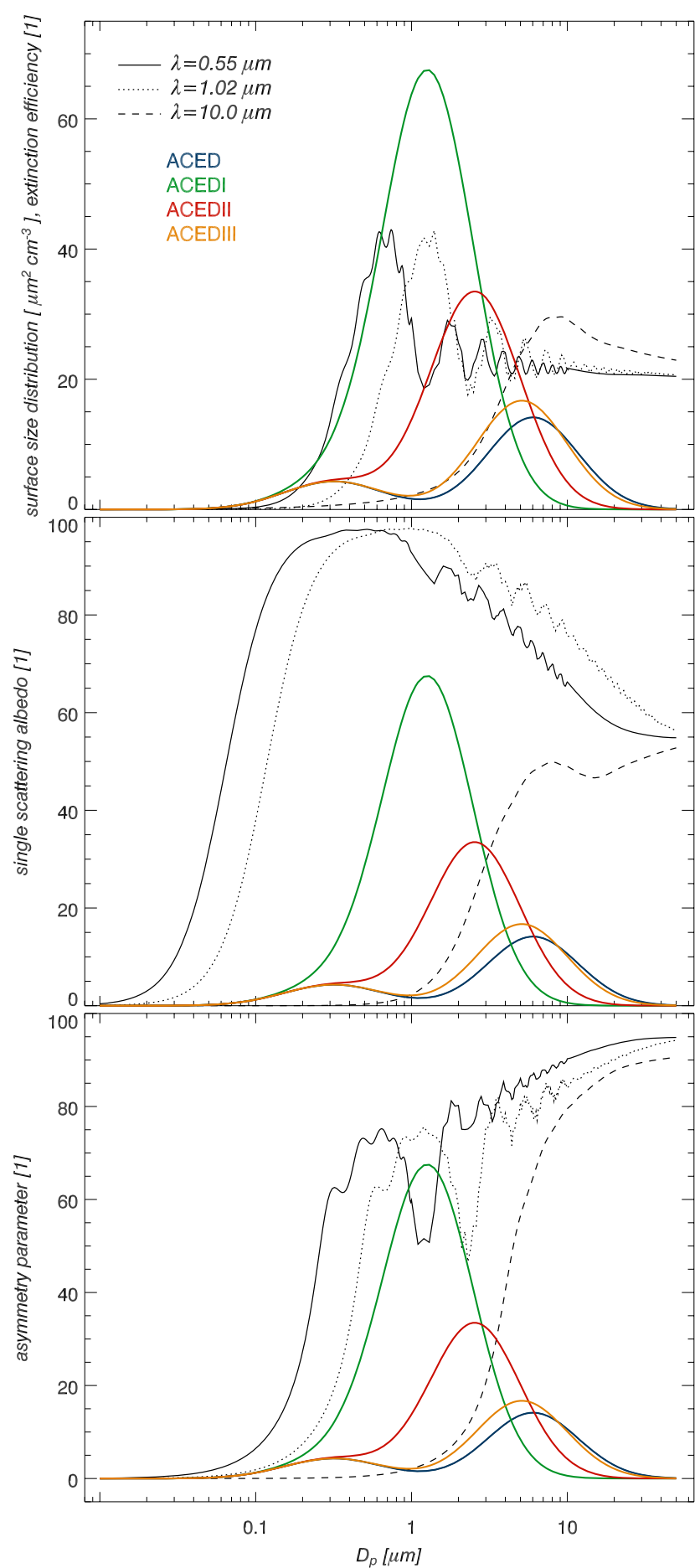

Fig. 16. Surface concentration size distributions (coloured) considering the data of Table 5 for the ACED and ACEDI-III compared to the size dependent optical properties (black) for the wavelengths $0.55,1.02$ and $10.0 \mu \mathrm{m}$, which were calculated via Mie scattering theory using the mean complex refractive index shown in Fig. 4. The extinction efficiencies (top) are multiplied by the factor of 10 , the single scattering albedos (center) and the asymmetry parameters (bottom) by 100 . 
Table 6. Atmospheric radiative effects (AREs) $\Delta F_{t}$ in $\mathrm{W} \mathrm{m}^{-2}$ for the dust scenarios ACEDI-IV as defined in the main text compared to the ACED varying the coarse mode median diameter $D_{p, 2}$ (cases ACEDI-III) and the total optical depth (case ACEDIV). The $\Delta F$ 's were calculated at TOA/BOA (upper/lower values) following the Eqs. (2) and (3) where the reference case is always the ACED. All computations were performed over the ocean $\left(T_{s}=22^{\circ} \mathrm{C}\right)$ and the desert $\left(35^{\circ} \mathrm{C}\right)$ using Mie scattering theory as well as the mean complex refractive index of Fig. 4.

\begin{tabular}{ccccc}
\hline Dust case & $\begin{array}{c}D_{p, 2} \\
{[\mu \mathrm{m}]}\end{array}$ & $\begin{array}{c}\tau(0.55) \\
{[1]}\end{array}$ & $\begin{array}{c}\text { Ocean } \\
\text { ARE }\end{array}$ & $\begin{array}{c}\text { Desert } \\
\text { ARE }\end{array}$ \\
\hline ACED & 9.45 & 0.311 & $\begin{array}{c}\text { Reference } \\
+85.3\end{array}$ & $\begin{array}{c}\text { Reference } \\
-28.6\end{array}$ \\
ACEDI & 2.0 & 1.495 & $\begin{array}{c}-185.4 \\
+143.5\end{array}$ \\
& & & +27.3 & -26.9 \\
ACEDII & 4.0 & 0.699 & -74.0 & -55.3 \\
& & & +2.4 & -6.0 \\
ACEDIII & 8.0 & 0.360 & -10.0 & -7.7 \\
& & & +10.5 & +23.5 \\
ACEDIV & 4.0 & 0.311 & +8.9 & +17.5 \\
\hline
\end{tabular}

concentration of the ACED remains fixed. The corresponding surface size distributions were adopted as constant at all model layers within the dust plumes to compute the optical properties. In addition, the scenario ACEDIV is defined by the ACEDII but with a scaled optical depth so that $\tau(0.55)$ equals the value for ACED (see Table 6).

Figure 16 shows the surface size distributions for the dust cases as defined before, which are needed to compute the optical properties. Note that for a constant total volume concentration the total particle surface increases with decreasing $D_{p, 2}$. The plots (top), (center) and (bottom) of Fig. 16 also depict the extinction efficiency, the single scattering albedo and the asymmetry parameter of a single spherical particle for three wavelengths $(0.55,1.02$ and $10.0 \mu \mathrm{m})$ as function of its diameter, calculated using Mie scattering theory and the mean complex refractive index of mineral dust (Fig. 4). This helps to interpret the optical impact of differently sized dust particles. From Fig. 16 (top) one can learn that the shortwave optical depth, i.e. the size integrated extinction efficiency, turns out the be larger the more $D_{p, 2}$ is shifted to smaller values. However, the optical depth in the terrestrial window region is predominantly affected by a larger $D_{p, 2}$. Figure 16 (center) shows that the shortwave single scattering albedo increases if $D_{p, 2}$ is reduced, while the shortwave asymmetry parameter (bottom) decreases with reduced $D_{p, 2}$. This situation is reversed in the longwave range for $\omega_{o}$. For example the column single scattering albedo of the ACED was calculated to about $\omega_{o}(0.55)=0.78$.

Table 6 presents the results of the ARE calculations at TOA for the dust scenarios as defined above. The cooling/warming over the ocean/desert is the weaker, the larger the $D_{p, 2}$ is. Therewith the role of the large particles is not degraded, since the total optical depth increases from case ACEDIII to ACEDI. If $\tau(0.55)$ of the ACED has been fixed as in the case of the ACEDIV, this scenario demonstrates the warming effect of large dust particles and underlines their key role, for both desert and ocean regions: The reflected/transmitted light at TOA/BOA increases for the ACEDIV with a reduced $D_{p, 2}$ resulting in positive AREs and atmospheric radiation losses $\Delta F_{t}(A)>0$. Moreover, ACEDII and ACEDIV indicate that, relative to the ACED, a fixed $D_{p, 2}$ but different total optical depths can lead to significant opposite AREs. On the other hand, one particular ARE may be caused by various dust aerosols with different contributions of the fine and coarse mode particles to the optical properties. This important fact has to be kept in mind when assessing radiative budget quantities from dust particle size distribution data or remote sensing dust size distribution information vice versa. Note that the complex refractive index of dust particles and their non-sphericity may depend on their size leading to even more complex situations.

\section{Conclusions}

Airborne measured number size distributions of mineral dust particles from the Sahara, observed on 8 July 1997 during ACE- 2 over the Canary Islands, were presented and used for comprehensive radiative transfer simulations. The optical properties of the dust layer were calculated via Mie scattering theory. It turned out that the asymmetry parameter $g$ and the single scattering albedo $\omega_{o}$ vary strongly with altitude between $g(0.55 \mu \mathrm{m})=0.65-0.81$ and $\omega_{o}(0.55)=0.75-0.96$. Within the dust layer, containing large particles with diameters $D_{p}>4 \mu \mathrm{m}, g(0.55)=0.81$ and $\omega_{o}(0.55)=0.76$ were found, which is in good agreement with other measurements performed during ACE-2 (Öström and Noone, 2000). The radiative transfer simulations show a dominant influence of the observed large particles on the extinction.

For the radiative transfer simulations of atmospheric radiative effects (AREs) two typical scenarios were considered: The measured dust over an ocean and desert surface, which differ significantly in the spectral albedo and temperature of the surface. The ACE-2 Saharan dust causes a cooling over ocean but a warming over desert. In particular, the large particles always heat the local atmosphere due to absorption and contribute at least $20 \%$ to the ARE. The magnitude of their warming effect is significantly influenced by the particle's spectral complex refractive index.

The measured size distributions were vertically integrated to derive the modal parameters of an assumed bimodal column volume size distribution leading to a coarse mode median diameter of $9.45 \mu \mathrm{m}$ and a column single scattering albedo in the visible $\omega_{o}(0.55)$ of 0.78 . The monomodal column volume size distribution calculated by Formenti et al. (2000) during ACE-2 shows a similar value of a median 
diameter with $\sim 5.5 \mu \mathrm{m}$ for 8 July 1997 but a somewhat larger column single scattering albedo of $\omega_{o}(0.5)=0.87$.

The column size distribution was used for sensitivity studies varying the coarse mode median diameter but leaving constant either the total dust particle volume concentration or the mid-visible optical depth. The results confirm the warming effect of the large particles and show significantly changed radiative effects as function of the variability of the coarse median diameter and total dust load.

The main purpose of this work was to explore the radiative effects of a Saharan mineral dust layer and the role of large dust particles. Quantitative radiative transfer simulations demonstrate that the variabilities and uncertainties in the spectral complex refractive index of the particles have a significant influence on the AREs. Therefore, the aim of future studies has to be to measure the large particles when present and to quantify the refractive index of mineral dust samples as function of wavelength and particle size. Beyond, for both the interpretation of optical measurements as well as radiative impacts of mineral dust the particle's non-sphericity as a function of size is expected to play an important role. These are crucial factors for more reliable simulations of dust optical properties and the radiative transfer through a dusty atmosphere. Additionally, in situ measurements, as e.g. lidar observations, of optical properties, surface albedo as well as shortwave and longwave radiation are required for a realisitic closure. In particular, multi-wavelength Raman lidar observations have to be exploited to obtain the vertical extinction profile of the dust at several wavelengths for use in radiative transfer simulations. Such in situ data have recently been carried out during the SAMUM experiment (http://samum.tropos.de/) in summer 2006 in Morocco.

Edited by: A. Hofzumahaus

\section{References}

Anderson, G. P., Clough, S. A., Kneiyzs, F. X., Chetwynd, J. H., and Shettle, E. P.: AFGL Atmospheric Constituent Profiles (0120 km), AFGL-TR-86-0110, AFGL (OPI), Hanscom AFB, MA 01736, 1986.

Carlson, T. N. and Benjamin, S. G.: Radiative heating rates for saharan dust, Am. Meteor. Soc., 37, 193-213, 1980.

Claquin, T., Schulz, M., Balkanski, Y., and Boucher, O.: Uncertainties in assessing radiative forcing by mineral dust. Tellus, 50B, 491-505, 1998.

Burrows, J. P., Dehn, A., Deters, B., Himmelmann, S., Richter, A., Voigt, S., and Orphal, J.: Atmospheric Remote-Sensing Reference Data from GOME: 1. Temperature-Dependent Absorption Cross Sections of NO2 in the 231-794 nm Range, J. Quant. Spectrosc. Radiat. Transfer, 60, 1025-1031, 1998.

Burrows, J. P., Dehn, A., Deters, B., Himmelmann, S., Richter, A., Voigt, S., and Orphal, J.: Atmospheric Remote-Sensing Reference Data from GOME: 2. Temperature-Dependent Absorption Cross Sections of O3 in the 231-794 nm Range, J. Quant. Spectrosc. Radiat. Transfer, 61, 509-517, 1999. de Reus, M., Dentener, F., Thomas, A., Borrmann, S., Ström, J., and Lelieveld, J.: Airborne observations of dust aerosol over the North Atlantic Ocean during ACE 2: Indications for heterogeneous ozone destruction, J. Geophys. Res., 105, 15 263-15 275, 2000a.

de Reus, M., Ström, J., Curtius, J., Pirjola, L., Vignati, E., Arnold, F., Hanson, H. C., Kulmala, M., Lelieveld, J., and Raes, F.: Aerosol production and growth in the upper free troposphere, J. Geophys. Res., 105, 24 751-24 762, 2000b.

Dufresne, J.-L., Gautier, C., and Ricchiazzi, P.: Longwave scattering effects of mineral aerosols, J. Atmos. Sci., 59, 1959-1966, 2002.

Formenti, P., Andreae, M. O., and Lelieveld, J.: Measurements of aerosol optical depth above $3570 \mathrm{~m}$ asl in the North Atlantic free troposphere: results from ACE-2, Tellus, 52B, 678-693, 2000.

Haywood, J. M, Francis, P. N., Glew, M. D., and Taylor, J. P.: Optical properties and direct radiative effect of Saharan dust: A case study of two Saharan dust outbreaks using aircraft data, J. Geophys. Res., 106(D16), 18 417-18 430, 2001.

Haywood, J., Francis, P., Osborne, S., Glew, M., Loeb, N., Highwood, E., Tanré, D., Myhre, G., Formenti, P., and Hirst, E.: Radiative properties and direct radiative effect of Saharan dust measured by the C-130 aircraft during SHADE: 1. Solar spectrum, J. Geophys. Res., 108(D18), 8577, doi:10.1029/2002JD002687, 2003.

Lafon, S., Sokolik, I. N., Rajot, J. L., Caquineau, S., and Gaudichet, A.: Characterization of iron oxides in mineral dust aerosols: Implifications for light absorption, J. Geophys. Res., 111, D21207, doi:10.1029/2005JD007016, 2006.

Liou, K. N., Fu, Q., and Ackerman, T. P.: A simple formulation of the delta-four-stream approximation for radiative transfer parameterizations, J. Atmos. Sci., 45(3), 1940-1947, 1988.

Molina, L. T. and Molina, M. J.: Absolute absorption cross sections of ozone in the 185- to 350-nm wavelength range, J. Geophys. Res., 91, 14 501-14 508, 1986.

Myhre, G. and Stordal, F.: Global sensitivity experiments of the radiative forcing due to mineral aerosols, J. Geophys. Res., 106, No. D16, 18193-18204, 2001.

Myhre, G., Grini, A., Haywood, J. M., Stordal, F., Chatenet, B., Tanré, D., Sundet, J. K., and Isaksen, I. S. A.: Modeling the radiative impact of the mineral dust during the Saharan Dust Experiment (SHADE) campaign, J. Geophys. Res., 108(D18), 8579, doi:10.1029/2002JD002566, 2003.

Nicolet, M.: On the molecular scattering in the terrestrial atmosphere: An empirical formula for its calculation in the homosphere, Planet. Space Sci., 32, 1467-1468, 1984.

Öström, E. and Noone, K. J.: Vertical profiles of aerosol scattering and absorption measured in situ during the North Atlantic Aerosol Characterization Experiment (ACE-2), Tellus, 52B, 526-545, 2000.

Patterson, E. M., Gilette, D. A., and Stockton, B. H.: Complex index of refraction between 300 and $700 \mathrm{~nm}$ for Saharan aerosol, J. Geophys. Res., 82, 3153-3160, 1977.

Quijano, A. L., Sokolik, I. N., and Toon, O. B.: Radiative heating rates and direct radiative forcing by mineral dust in cloudy atmospheric conditions, J. Geophys. Res., 105(D10), 12 207-12 219, 2000a.

Quijano, A. L., Sokolik, I. N., and Toon, O. B.: Influence of the aerosol vertical distribution on the retrievals of aerosol optical 
depth from satellite radiance measurements, Geophys. Res. Letters, 27(21), 3457-3460, 2000b.

Raes, F., Bates, T., McGovern, F., and van Liedekerke, M.: The 2nd Aerosol C haracterization Experiment (ACE-2): general overview and main results, Tellus, 52B, 111-125, 2000.

Rufus, J., Stark, G., Smith, P. L., Pickering, J. C., and Thorne, A. P.: High resolution photoabsorption cross section measurements of SO2 at $295 \mathrm{~K}$ between 220 and $325 \mathrm{~nm}$, J. Geophys. Res.: Planets, 108(E2), 5011, doi:10.1029/2002JE001931, 2003.

Schröder, T.: Fernerkundung von Wasserinhaltsstoffen in Küstengewässern mit MERIS unter Anwendung expliziter und impliziter Atmosphärenkorrekturverfahren, Dissertation, Freie Universität Berlin, 113 p., http://www.diss.fu-berlin.de/2005/ 78/, 2004.

Shettle, E. P. and Fenn, R. W.: Models of the Aerosols of the Lower Atmosphere and the Effects of Humidity Variations on their Optical Properties. Project 7670, Air Force Geoph. Lab., Massachusetts, 1979.

Smirnov, A., Holben, B. N., Slutsker, I., Welton, E. J., and Formenti, P.: Optical properties of Saharan dust during ACE 2, J. Geoph. Res., 103(D21), 28 079-28 092, 1998.

Sokolik, I., Andronova, A., and Johnson, T. C.: Complex refractive index of atmospheric dust aerosols, Atm. Envir., 27A, 24952502, 1993.

Sokolik, I., Toon, O. B., and Bergstrom, R. W.: Modeling the radiative characteristics of airborne mineral aerosols at infrared wavelengths, J. Geoph. Res., 103(D8), 8813-8826, 1998.

Sokolik, I.: Nuts and bolts of radiative forcing by mineral dust. IGAC Newsletter, No. 17, 1999.
Sokolik, I. N. and Toon, O. B.: Incorporation of mineralogical composition into models of the radiative properties of mineral aerosol from UV to IR wavelengths. J. Geophys. Res., 104, 9423-9444, 1999.

Stamnes, K., Tsay, S., Wiscombe, W., and Jayaweera, K.: Numerically stable algorithm for discrete-ordinate-method radiative transfer in multiple scattering and emitting layered media, Appl. Opt., 27, 2502-2509, 1988.

Vandaele, A. C., Hermans, C., Simon, P. C., Carleer, M., Colin, R., Fally, S., Merienne, M.-F., Jenouvrier, A., and Coquart, B.: Measurements of the NO2 absorption cross-section from $42000 \mathrm{~cm}$ 1 to $10000 \mathrm{~cm}-1(238-1000 \mathrm{~nm})$ at $220 \mathrm{~K}$ and $294 \mathrm{~K}$, J. Quant. Spectrosc. Radiat. Transfer, 59, 171-184, 1998.

Volz, F. E.: Infrared absorption by atmospheric aerosol substances, J. Geophys. Res., 77, 1017-1031, 1972.

Volz, F. E.: Infrared optical constants of ammonium sulphate, Sahara dust, volcanic pumice and flyash, Appl. Opt., 12, 564-568, 1973.

Wang, H., Shi, G., Li, S., Li, W., Wang, B., and Huang, Y.: The impact of optical properties on radiative forcing due to dust aerosol, Adv. in Atmos. Sci., 23(3), 431-441, 2006.

Weaver, C. J., Ginoux, P., Hsu, N. C., Chou, M.-D., and Joiner, J.: Radiative forcing of Saharan dust: GOCART model simulations compared with ERBE data, J. Atmos. Sci., 59, 736-747, 2002.

Zhang, J. and Christopher, S. A.: Longwave radiative forcing of Saharan dust aerosols estimated from MODIS, MISR, and CERES observations on Terra, Geophys. Res. Lett., 30(23), 2188, doi:10.1029/2003GL018479, 2003. 